\title{
Resveratrol Ameliorates Lipid Droplet Accumulation in Liver Through a SIRT1/ ATF6-Dependent Mechanism
}

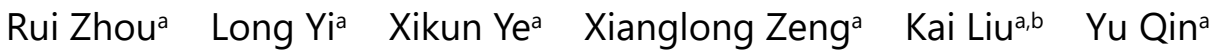 \\ Qianyong Zhang ${ }^{\mathrm{a}}$ Mantian $\mathrm{Mi}^{\mathrm{a}}$
}

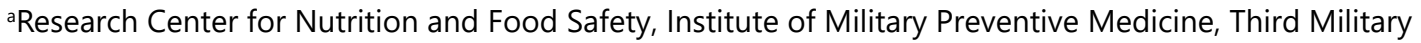
Medical University, Chongqing Key Laboratory of Nutrition and Food Safety, Chongqing, 'b Department of Health Supervision, Center for Disease Control and Prevention of Shenyang Joint Logistic Support Center, Shenyang, China

\section{Key Words \\ Lipid droplets $\cdot$ SIRT1 $•$ ATF6 $・$ Resveratrol $・$ NAFLD}

\begin{abstract}
Background/Aims: Lipid droplets (LDs) are dynamic organelles that store neutral lipids during times of energy excess, and an increased accumulation of LDs in the liver is closely linked to hepatic steatosis. Our previous studies suggested that resveratrol (RSV) supplement could improve hepatic steatosis, but the underlying mechanism, particularly which related to LD accumulation, has not yet been elucidated. Methods: A high-fat diet (HFD) and palmitic acid were used to induce hepatic steatosis in mouse liver and hepatocytes, respectively. The effects of RSV on LD accumulation were analyzed in vivo and in vitro. The effects of RSV on the expression levels of LD-associated genes (ATF6, Fsp27ß/CIDEC, CREBH, and PLIN1) were measured by qRT-PCR and western blot assays, followed by KD or overexpression of SIRT1 and ATF6 with small interfering RNAs or overexpressed plasmids, respectively. The dual luciferase reporter assay, chromatin immunoprecipitation assay, coimmunoprecipitation, and proximity ligation assay were utilized to clarify the mechanism of transcriptional regulation and possible interaction between SIRT1 and ATF6. Results: There was a significant increase in the accumulation of LDs in liver and hepatocytes during the process of HFD-induced steatosis, respectively, which was significantly inhibited by RSV supplementation. RSV notably activated SIRT1 expression and decreased the expression levels of ATF6, Fsp27 $\beta / C I D E C, C R E B H$, and PLIN1, which are associated with LD accumulation. Interestingly, the inhibitory effects of RSV on LD accumulation and the associated expression of genes in hepatocytes were abrogated or strengthened with SIRT1 silencing or overexpression, respectively. On the contrary, the benefits of RSV in hepatocytes were eliminated or aggravated when transfected with the overexpressed ATF6 or ATF6 siRNA, respectively. Furthermore, we found that RSV stimulated SIRT1 expression significantly, which was followed by increased deacetylation and inactivation R. Zhou and L. Yi contributed equally to this work.
\end{abstract}

Mantian Mi

KARGER
Research Center for Nutrition and Food safety, Third Military Medical University, 30th Gaotanyan Main Street, Chongqing 400038 (China)

Tel. +86 2368771549, E-Mail mi_mt2009@hotmail.com 


\section{Cellular Physiology Cell Physiol Biochem 2018;51:2397-2420

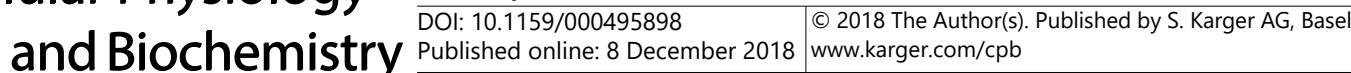 \\ Zhou et al.: Resveratrol Ameliorates LDs Through SIRT1/ATF6}

of ATF6, resulting in a positive feedback loop for SIRT1 transcription associated with ATF6 binding to the SIRT1 promoter region. Conclusion: Taken together, these findings indicate that RSV supplementation improves hepatic steatosis by ameliorating the accumulation of LDs, and this might be partially mediated by a SIRT1/ATF6-dependent mechanism.

(c) 2018 The Author(s)

Published by S. Karger AG, Basel

\section{Introduction}

Non-alcoholic fatty liver disease (NAFLD) is a growing but serious threat to public health around the world, in part due to the accumulation of triglycerides (TGs) and free fatty acids (FAs) in the liver. It encompasses a spectrum of liver lesions ranging from simple hepatic steatosis to non-alcoholic steatohepatitis (NASH) that can further evolve to fibrosis, cirrhosis, and finally hepatocellular carcinoma [1]. NAFLD patients are at increased risk of liver-related diseases and have an elevated risk of cardiovascular disease and mortality, and NAFLD is rapidly becoming the leading indication for liver transplantation [2]. The mechanism underlying NAFLD pathophysiology remains elusive; however, a "two-hit" hypothesis has been suggested as a possible mechanism of pathological change in chronic liver disease [3]. Simple hepatic steatosis caused by lipid accumulation represents the "first hit" in the pathological process [4]. Lipid droplets (LDs) are a form of lipid accumulation, which represents an early pathophysiological feature of altered liver metabolism [5]. LDs are subcellular organelles that store neutral lipids during times of energy excess and serve as an energy reservoir during deprivation. Furthermore, the quantity and sizes of the LDs reflect different biological progresses. Abnormal lipid accumulation in LDs in the liver are associated with many prevalent metabolic diseases, including NAFLD [6]. Some proteins closely associated with lipid accumulation in hepatic cells are located on the LDs. In particular, fat-specific protein $27 \beta$ (Fsp27 $\beta$, CIDEC in humans) is a lipid-coating protein highly expressed in mature adipocytes and plays an essential role in the formation of LDs in association with other factors, such as perilipin1 (PLIN1) [7]. Knockdown (KD) of Fsp27 $\beta$ / CIDEC expression in well-differentiated adipocytes enhances lipolysis and increases the number of mitochondria, while forced expression of Fsp27 $\beta /$ CIDEC in 3T3-L1 adipocytes causes the formation of unilocular LDs [8]. Fsp27 $\beta /$ CIDEC null mutation protects mice from obesity, hepatosteatosis, and insulin resistance (IR) induced by a high-fat diet (HFD) in association with changes in energy expenditure [9]. F Furthermore, Fsp27 $\beta /$ CIDEC is reported to be a steatosis- and steatohepatitis-specific gene, which marks the pathogenesis of NAFLD $[10,11]$. Thus, Fsp27 $\beta /$ CIDEC is a key player in the development and progression of NAFLD.

Mammalian sirtuins, the silent information regulator 2 family, consist of seven members (SIRT 1-7) and belong to a group of class III histone/protein NAD+-dependent deacetylases. They are key regulators in a plethora of cellular processes, including hepatic glucose and FA metabolism, mitochondrial functions, insulin secretion, adipocyte maturation, and even endoplasmic reticulum (ER) stress and the unfolded protein response (UPR) [12]. Studies on mice and cultured cells have provided direct evidence that SIRT1 is involved in the regulation of both lipid and carbohydrate metabolism in the liver and in the development of NAFLD [13]. SIRT1 levels are reduced by a HFD, while calorie restriction (CR) results in elevated expression and an improvement in NAFLD histology [14]. Recent studies have shown a correlation between plasma SIRT1 and NAFLD in obese patients. SIRT1 levels were found to be significantly lower in an obese group with severe liver steatosis compared with a group with mild steatosis, and both groups had lower levels in the plasma compared with control lean patients $[15,16]$. It has long been known that obesity and NAFLD lead to ER stress and the UPR [17]. As one of three ER stress transducers, activating transcription factor 6 (ATF6) is a basic region-leucine zipper (bZip) transcription factor that exerts its effects on hepatic lipid accumulation and inflammation through its downstream targets. cAMP response element-binding protein $\mathrm{H}$ (CREBH) is another ER-bound bZIP family transcription factor belonging to the CREB/ATF family, and its expression is restricted to the liver [18]. It plays 


\section{Cellular Physiology Cell Physiol Biochem 2018;51:2397-2420

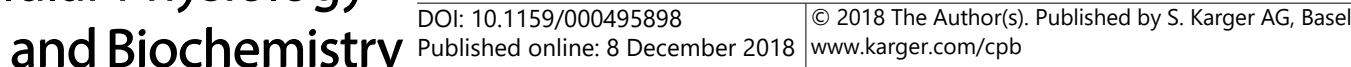 \\ Zhou et al.: Resveratrol Ameliorates LDs Through SIRT1/ATF6}

an important role in the regulation of hepatic lipogenesis, FA oxidation, and lipolysis under metabolic stress [19]. A previous study demonstrated that the inhibition of CREBH helps to prevent increases in Fsp27 mRNAs in alcoholic steatohepatitis in mice and humans [20].

Although NAFLD poses a big challenge to human health, there are no effective treatments available yet other than lifestyle modifications such as CR and physical exercise. Resveratrol (RSV) is a polyphenol found in grapes and other plants and it is reported to have many beneficial effects in humans, including reduced obesity, IR, dyslipidemia, NAFLD, and the prevention of tumorigenesis [21]. Previously, we found that RSV supplementation in patients with NAFLD has a beneficial effect on liver enzymes and lipid metabolism [22]. However, a meta-analysis of placebo-controlled clinical trials concluded that treatment with RSV has negligible effects on NAFLD [23]. SIRT1 has been considered a potential target of RSV since the first report of its effects on SIRT1 activation in a yeast in 2003 [24]. We have previously shown that RSV can improve hepatic steatosis in hepatocytes in vitro by inducing autophagy through a SIRT1-dependent action via activation of the cAMP-protein kinase A-AMP-activated protein kinase (AMPK) signaling pathways [25]. However, the role of RSV in hepatic lipid metabolism and, in particular, the accumulation of LDs remain unclear. Thus, we hypothesized that RSV could attenuate the accumulation of LDs via the regulation of LDassociated gene expression through a SIRT1/ATF6-dependent mechanism in NAFLD mouse and cell models. As expected, our results indicated, for the first time, that RSV strongly attenuated hepatic steatosis and reduced LD accumulation in mouse liver and hepatocytes. Furthermore, the benefits induced by RSV might be ascribed to the downregulation of LDassociated genes through the stimulation of SIRT1, leading to increased deacetylation and inactivation of ATF6, and finally resulting in a positive feedback loop for SIRT1 transcription associated with ATF6 binding to the SIRT1 promoter region. The findings provide new insights into the beneficial impact of RSV on the accumulation of LDs in liver and will ultimately lead to the design of molecular therapies aimed at improving NAFLD.

\section{Materials and Methods}

\section{Chemicals and reagents}

RSV (R5010), was purchased from Sigma-Aldrich (St. Louis, M0). The purity of RSV was determined to be greater than $98 \%$ by high-performance liquid chromatography. Cell culture supplies, such as culture media and fetal bovine serum (FBS), were obtained from Hyclone (Carlsbad, CA). Palmitate acid (PA, P5585) and Oil Red 0 (00625) were purchased from Sigma-Aldrich. Antibodies against SIRT1 (2028) and PLIN1 (9349) were obtained from Cell Signaling Technology, Inc. (Danvers, MA). Antibodies against ATF6 (PA520215) and CIDEC/Fsp27 $\beta$ (PA1-46128) were purchased from Thermo Fisher Scientific (Rockford, IL). Antibodies against CREBH were purchased from Santa Cruz Biotechnology, Inc. (Santa Cruz, CA). Actin (TA09) were obtained from Zhongshan Jinqiao Biotechnology (Beijing, China). SIRT1 small interfering RNA (siRNA) was purchased from Cell Signaling Technology, and ATF6 siRNA was constructed by GeneCopoeia Inc. (Guangzhou, China).

\section{Animal experiments}

The animals were used and cared for in accordance with our institutional guidelines for the use of laboratory animals. All animal procedures were approved by the Animal Ethics Committee of the Third Military Medical University (SYXC-2013-00012). Twenty-five male mice (C57BL/6, 4-6 weeks old) were purchased from the Medical Experimental Animal Center of the Third Military Medical University. Mice were first fed with either a chow diet or HFD (containing 60\% fat) for 2 weeks to induce hepatic steatosis. The HFD and chow were obtained from Mediscience Ltd. (Jiangsu, China). Thereafter, the HFD-fed mice were either administered or not administered intragastric RSV of $400 \mathrm{mg} / \mathrm{kg} / \mathrm{day}$ [26] for 30 days accompanied by the presence or absence of a pAAV-ZsGreen-shRNA-mSIRT1 plasmid (Fig. S2A - For all supplemental material see www.karger.com/10.1159/000495898) injection through the tail vein every 5 days. The pAAV-ZsGreen-shRNA-mSIRT1 plasmid was synthesized by Life Technology (Shanghai, China). For each injection, $12.5 \mu \mathrm{g}$ of shSIRT1 with $25 \mu \mathrm{L}$ of a non-liposomal nanoparticle transfection reagent (Entranster- 


\section{Cellular Physiology Cell Physiol Biochem 2018;51:2397-2420

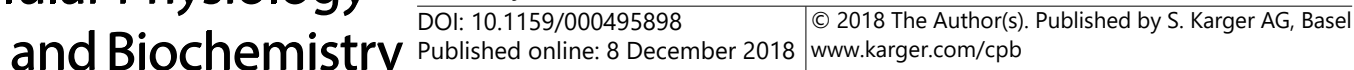

in vivo; Engreen Biosystem Co. Ltd., Beijing, China) in a $10 \%$ glucose solution was used according to the manufacturer's protocol [27]. All animals were monitored for activity, physical condition, and body weight. Body weights were examined every 2 days. After 30 days, mice were sacrificed by $\mathrm{CO}_{2}$ inhalation. Serum was prepared by solidification and centrifugation $\left(3,000 \times \mathrm{g}, 10 \mathrm{~min}, 4{ }^{\circ} \mathrm{C}\right)$ and kept frozen at $-80{ }^{\circ} \mathrm{C}$ until analysis of the biochemical parameters. The livers were carefully removed, weighed, photographed, and then homogenized with RIPA lysis buffer (20 mg liver tissue/300 $\mu \mathrm{L}$ RIPA) in preparation for western blotting. Other tissues were frozen immediately in liquid nitrogen and stored at $-80{ }^{\circ} \mathrm{C}$ for hepatic and plasma TG measurements, real-time RT-PCR, and other experiments. Plasma RSV concentration was determined by liquid chromatography-mass spectrometry as described previously [28].

\section{Histological analysis}

Tissues were fixed in neutral-buffered formalin for histological examination. Dehydrated tissues were mounted in xylene and subsequently embedded into paraffin. Paraffin blocks were cut into 5- $\mu$ mthick sections for hematoxylin and eosin staining. Fresh liver samples were frozen fixed in optimal cutting temperature mounting media (Leica Microsystems, Wetzlar, Germany) for Oil Red 0 staining to visualize hepatic lipids. All sections were analyzed by microscopy [29].

\section{Cell culture and treatment}

Human HepG2 cells were obtained from the American Type Culture Collection and cultured in Dulbecco's modified Eagle's medium (DMEM) supplemented with $10 \%$ FBS at $37{ }^{\circ} \mathrm{C}$ in a humidified atmosphere enriched with $5 \% \mathrm{CO}_{2}$. All experiments were performed when the cells reached about 80-90\% confluence. Mouse primary hepatocytes were isolated from C57BL/6 mice as described previously [8]. The isolated hepatocytes were seeded at a density of $1 \times 10^{6}$ cells per flask in DMEM containing 1.9\% HEPES, $0.9 \%$ glutamine, $0.3 \%$ insulin, $0.2 \%$ dexamethasone, and $0.9 \%$ penicillin-streptomycin. HepG2 cells and primary hepatocytes were treated with different doses $(0.1,0.2,0.3,0.4$, and $0.5 \mathrm{mM})$ of PA for $24 \mathrm{~h}$ to induce steatosis. After successfully producing a hepatic steatosis model in vitro, cells were treated with or without a series of concentrations $(10,20$, and $40 \mu \mathrm{M})$ of RSV for another $24 \mathrm{~h}$.

\section{Cell viability measurements}

The viability of hepatocytes was measured using a Cell Counting Kit-8 as described previously [30]. Briefly, cells were seeded in a 96-well microplate (3650; Corning Life Sciences, Acton, MA) at a density of 5 $\times 10^{3}$ cells/well for $24 \mathrm{~h}$, followed by exposure to the indicated treatments. Cell Counting Kit- 8 solution (10 $\mu \mathrm{L}$ ) was then added to each well, and cells were incubated at $37{ }^{\circ} \mathrm{C}$ for $1 \mathrm{~h}$. Cell viability was then detected via absorbance measurements $(450 \mathrm{~nm})$ using a monochromator microplate reader (Safire II; Tecan Group Ltd., Männedorf, Switzerland). The optical density at $450 \mathrm{~nm}$ was reported as the percentage of viable cells in relation to the control group (set as $100 \%$ ).

\section{SIRT1 activity assay}

SIRT1 activity was measured using a SIRT1 activity fluorescent quantitative assay kit (Genmed Scientifics Inc., Wilmington, DE) according to the manufacturer's instructions. The fluorescence intensity at $450 \mathrm{~nm}$ (exc. $350 \mathrm{~nm}$ ) was measured immediately after the addition of fluorosubstrate peptide. The results are reported as relative fluorescence. The assays were repeated three times.

\section{RNA interference and lentivirus transfection}

The SIRT1-overexpressed lentivirus vector (LV-SIRT1) and the empty vector (LV-empty) were kindly provided by Dr. Yuming Li (Department of Hepatobiliary Surgery, Second Affiliated Hospital of Third Military Medical University, Chongqing, China). p3×FLAG-ATF6 plasmid and its corresponding control vector pCMV3FLAG-7.1 were obtained from Addgene (\#11975; Cambridge, MA) (Fig. S2B). The vectors were transfected into HepG2 cells using Lipofectamine 2000 (11668-027; Invitrogen, Carlsbad, CA) according to the manufacturer's instruction. For the siRNA experiment, after seeding for $24 \mathrm{~h}$, HepG2 cells were transfected with the corresponding siRNA using Lipofectamine 2000. After transfection, cells were exposed to $0.2 \mathrm{mM}$ of PA for an additional $24 \mathrm{~h}$ and treated with different concentrations of RSV for a further $24 \mathrm{~h}$. 


\section{Cellular Physiology Cell Physiol Biochem 2018;51:2397-2420 and Biochemistry \begin{tabular}{l|l} 
DOI: 10.1159/000495898 & 2018 The Author(s). Published by S. Karger AG, Basel \\
wubw.karger.com/cpb
\end{tabular}

Lipid content measurements

Hepatic lipid accumulation was detected by Oil Red 0 staining as described previously [31]. Briefly, the primary hepatocytes and HepG2 cells were cultured overnight at a density of $1 \times 10^{4}$ cells per well in a 24-well microplate (3650; Corning Life Sciences) and subjected to the indicated treatments. The cells were then fixed in $4 \%$ paraformaldehyde for $20 \mathrm{~min}$, washed three times with phosphate-buffered saline, and stained with $0.5 \%$ Oil Red 0 for $10 \mathrm{~min}$ at room temperature. Images were captured under a microscope. The TG levels of liver tissues and hepatocytes were measured by a TG assay kit (A110-1; Nanjing Jiancheng Bioengineering Institute, Jiangsu, China).

\section{Biochemical parameters}

Serum total cholesterol (TC), high density lipoprotein cholesterol (HDL-C), low density lipoprotein cholesterol (LDL-C) were quantified using enzymatic assays (Nanjing Jiancheng Bioengineering Institute, Jiangsu, China) according to the manufacturer's instructions.

\section{Transmission electron microscopy}

Routine methods to prepare liver specimens for transmission electron microscopy were performed using at least 3 animals from each group. Fragments of liver tissue $\left(1 \mathrm{~mm}^{3}\right)$ were fixed in $2.5 \%$ glutaraldehyde in $0.1 \mathrm{M}$ cacodylate buffer ( $\mathrm{pH}$ 7.2) for $2 \mathrm{~h}$ at room temperature [32]. HepG2 cells were collected and prepared as described previously [30]. Briefly, cells were fixed in $2 \%$ paraformaldehyde and $0.1 \%$ glutaraldehyde in $0.1 \mathrm{M}$ sodium cacodylate overnight, post-fixed with $1 \%$ osmium tetroxide for $1.5 \mathrm{~h}$, washed, and stained for $1 \mathrm{~h}$ in $3 \%$ aqueous uranyl acetate. Ultrathin sections were cut on an ultramicrotome (Reichert-Jung, Inc., Cambridge, UK) and counterstained with $0.3 \%$ lead citrate. The tissue and cell sections were examined by a transmission electron microscope (model no. EM420; Koninklijke Philips Electronics N.V., Amsterdam, The Netherlands).

\section{Fluorescent microscopic imaging}

After the indicated treatments, HepG2 cells were fixed with $4 \%$ paraformaldehyde for 30 min at room temperature. Cells were then treated with $0.1 \%$ Triton X-100 for 20 min and blocked with $10 \%$ goat serum for $1 \mathrm{~h}$ at room temperature. The primary antibodies for Fsp $27 \beta$ or CIEDC were added and the reaction was incubated overnight at $4{ }^{\circ} \mathrm{C}$. Anti-rabbit IgG antibody conjugated with Alexa Fluor 488 (A11008; Molecular Probes, Eugene, OR) was used as a secondary antibody. Bodipy 558/568 (D3835; Molecular Probes) was used for lipid staining. The nuclei were counterstained with 4',6-diamidino-2-phenylindole (DAPI) for 5 min at room temperature. The sections were observed under a Zeiss $200 \mathrm{M}$ inverted microscope, and the images were collected using a confocal laser scanning microscope (TCS SP2; Leica Microsystems GmbH).

\section{Western blotting analysis}

Hepatocytes $\left(1 \times 10^{6}\right)$ cultured in $100 \mathrm{~mm}^{2}$ culture dishes were treated as indicated. Whole cell lysates were obtained by cell lysis in ice cold RIPA buffer and subjected to sodium dodecyl sulfate polyacrylamide gel electrophoresis (SDS-PAGE), according to a previously reported procedure [33]. The polyvinylidene fluoride membrane was incubated with the appropriate primary antibody overnight at $4{ }^{\circ} \mathrm{C}$ with gentle shaking. The membrane was then incubated with a goat anti-mouse/rabbit IgG horseradish peroxidaseconjugated antibody (Bio-Rad Laboratories, Hercules, CA). Conjugated proteins were detected by the Fusion FX5 Spectra instrument from Vilber Lourmat Inc. (Paris, France).

RNA extraction and real-

\section{time RT-PCR}

Total RNA from HepG2 cells was extracted using the Trizol reagent from BioFlux (Hangzhou Bioer Technology Co., Ltd., Hangzhou, China). A 1- $\mu$ g aliquot of RNA from each sample was reverse transcribed. The primer
Table 1. Primers

\begin{tabular}{lll}
\hline Primer & \multicolumn{1}{c}{ Forward $\left(5^{\prime}-3^{\prime}\right)$} & \multicolumn{1}{c}{ Reverse $\left(5^{\prime}-3^{\prime}\right)$} \\
\hline SIRT1 & TAGCCTTGTCAGATAAGGAAGGA & ACAGCTTCACAGTCAACTTTGT \\
PLIN1 & TGGCACATACCCTGCAGAAG & ATGTCCCGGAATTCGCTCTC \\
ATF6 & GACAGTACCAACGCTTATGCC & CTGGCCTTTAGTGGGTGCAG \\
CREBH & ACTTCCTATGTATCCCTCAAAG & CTCATTGTCTTGTCTCTTGGT \\
CIDEC & ATTGATGTGGCCCGTGTAACG & CAGCAGTGCAGATCATAGGAAA \\
Fsp27 $\beta$ & TCGTGTTAGCACCGCAGAT & GCTCTCTTCTTGCGCTGTT \\
ATF6 ChIP & CACACGTTTGAAGCCAAGCT & CCCATCACTTGTAGGGTGGT \\
GAPDH & CAACTTTGGTATCGTGGAAGGAC & ACAGTCTTCTGGGTGGCAGTG \\
\hline
\end{tabular}




\section{Cellular Physiology Cell Physiol Biochem 2018;51:2397-2420 \begin{tabular}{l|l|l} 
and Biochemistry Published online: 8 December 2018 & $\begin{array}{l}\text { (c) } 2018 \text { The Author(s). Published by S. Karger AG, Basel } \\
\text { www.karger.com/cpb }\end{array}$ \\
\hline
\end{tabular}

sequences used for gene amplification are shown in Table 1. With an iQ5 machine (Bio-Rad Laboratories), a $25-\mu \mathrm{L}$ reaction mixture was amplified using the following thermal parameters: denaturation at $95^{\circ} \mathrm{C}$ for 30 $\mathrm{s}, 40$ cycles of the amplification step $\left(95^{\circ} \mathrm{C}\right.$ for $5 \mathrm{~s}$ and $60^{\circ} \mathrm{C}$ for $\left.34 \mathrm{~s}\right)$, and a final extension at $95^{\circ} \mathrm{C}$ for $15 \mathrm{~s}$ and $30^{\circ} \mathrm{C}$ for $6 \mathrm{~s}$. All amplification reactions were analyzed by the comparative threshold cycle (Ct) method and normalized to the level of GAPDH mRNA, which served as a control.

\section{Co-immunoprecipitation}

Whole-cell lysates in $500 \mu \mathrm{L}$ were pre-cleared with $15 \mu \mathrm{L}$ of protein A/G plus-agarose (sc-2003; Santa Cruz Biotechnology) for $2 \mathrm{~h}$ at $4{ }^{\circ} \mathrm{C}$. After centrifugation, the supernatants were incubated with an antiSIRT1 antibody overnight at $4{ }^{\circ} \mathrm{C}$. The beads were washed, and the protein complex was resolved on $12 \%$ SDS-PAGE, transferred to the membrane, and blotted with an anti-ATF6 antibody.

\section{Dual-luciferase reporter assay}

Luciferase activities were measured using the Dual-Luciferase Reporter Assay System (Promega, Madison, WI) $48 \mathrm{~h}$ after RSV treatment according to the manufacturer's protocol. ATF6 in the human SIRT1 promoter region was predicted using three online algorithms, NUBLScan, TRANSFAC, and Gene-Regulation. Based on the over-lapping findings from the predictions, a 1.2-kb human SIRT1 promoter sequence $(-1100$ to $+100 \mathrm{bp}$ ) was synthesized and cloned into the XhoI and HindIII sites of the pGL3-Basic vector (Fig. S2C) by Life Technology and then transfected into HepG2 cells with Lipofectamine 2000 (Invitrogen) according to the manufacturer's instructions. The resulting construct was confirmed by DNA sequencing. HepG2 cells were transfected with the pGL3-Basic-SIRT1 plasmid and co-transfected with the siRNA for ATF6 or a p3×FLAG-ATF6 plasmid and a pRL-TK plasmid (Promega). Firefly luciferase activity was measured and normalized for transfection efficiency via Renilla luciferase activity. All measurements were performed in triplicate, and the assays were repeated three times in HepG2 cells.

\section{Chromatin immunoprecipitation (ChIP) analysis}

ChIP assays were performed using a ChIP kit (Millipore, Billerica, MA) as described [34]. Briefly, HepG2 cells were treated with PA $(0.2 \mathrm{mM})$ or vehicle control $(0.1 \%$ ethanol) for $24 \mathrm{~h}$, and then fixed with $1 \%$ formaldehyde for $10 \mathrm{~min}$ at $37^{\circ} \mathrm{C}$ to cross-link the nuclear proteins to DNA. Subsequently, the cells were collected and lysed in sodium dodecyl sulfate (SDS) lysis buffer. The chromatin was sonicated to shear the DNA to an average length of 200-1000 bp, and then immunoprecipitated with $2 \mu \mathrm{g}$ antibody against ATF6, taking IgG as a negative control. The precipitated DNAs were extracted and amplified by PCR or qPCR with the primer pairs that cover the ATF6 in SIRT1 promoter region $(\sim 771$ to $\sim 763)$. The total DNA extract (input) was used as positive PCR control.

\section{Proximity ligation assay (PLA)}

A Duolink PLA protein detection kit was obtained from Sigma-Aldrich (DU092101-KT) and performed as described previously [35]. Cells were incubated in 24-well plates with RSV or PA for $24 \mathrm{~h}$ and fixed using cold 4\% paraformaldehyde. Fixed cells were used for the PLA assay. Cells were incubated with primary antibodies for $12 \mathrm{~h}$, washed, and secondary antibodies were added. After incubation and washing, ligation buffer and amplification solution were added according to the manufacturer's instructions. Cells were covered with a glass plate after mounting medium was added. Slides were viewed using an inverted microscope and two-photon fluorescence microscopy. IgG was used as a negative control. Images were obtained at $63 \times$ magnification.

\section{Immunoprecipitation}

HepG2 cells were treated with PA in the presence or absence of RSV. Thereafter, cells were lysed with cell lysis buffer (P0013; Beyotime Institute of Biotechnology, Shanghai, China). Lysates were clarified by centrifugation at $12,000 \times \mathrm{g}$ for $15 \mathrm{~min}$ and used for immunoprecipitation. A total of $2 \mathrm{mg}$ of antibodies was incubated with 500-1000 mg of protein overnight at $4{ }^{\circ} \mathrm{C}$. Next, protein A beads (P2006; Beyotime Institute of Biotechnology) were added and the mixture was incubated overnight at $4{ }^{\circ} \mathrm{C}$. After incubation, the beads were washed three times, solubilized in $40 \mathrm{~mL} 3 \times$ SDS sample buffer (7722; Cell Signaling Technology), and analyzed by western blotting. 


\section{Cellular Physiology Cell Physiol Biochem 2018;51:2397-2420 and Biochemistry Published online: 8 December 2018 \begin{tabular}{l|l} 
DOI: 2018 The Author(s). Published by S. Karger AG, Basel \\
www.karger.com/cpb
\end{tabular} \\ Zhou et al.: Resveratrol Ameliorates LDs Through SIRT1/ATF6}

\section{Statistical Analysis}

The data for the different treatment groups are presented as the mean \pm standard error unless otherwise stated. A one-way analysis of variance was used to determine the significance of the differences among three or more groups. A repeated measures analysis of variance was used to determine the significance of the in vivo findings. Comparisons between two groups were made by two-tailed unpaired $t$ test. The results were considered to be statistically significant when $P<0.05$.

\section{Results}

RSV protects against HFD-induced hepatic steatosis in mouse liver through SIRT1

Mice were fed a HFD to induce hepatic steatosis in vivo as reported previously [36]. They were initially fed a chow diet or HFD for 2 weeks, and then the HFD-fed mice were administered or not administered intragastric RSV at $400 \mathrm{mg} / \mathrm{kg} /$ day for 30 days accompanied by the presence or absence of a pAAV-ZsGreen-shRNA-mSIRT1 plasmid injection through the tail vein every 5 days (Fig. 1A). The mice were weighed after feeding every 2 days. The HFD group showed increased body weight and liver weight compared with the control group, but these were markedly reduced by the addition of RSV (Fig.1B and C). To examine the role of SIRT1 in the regulation of hepatic lipid storage by RSV, an SIRT1 shRNA was injected in the C57BL/ 6 mice every 5 days. As shown in Fig. 1B, SIRT1 KD mice with HFD gained more weight than wild-type (WT) mice fed with chow or a HFD, whereas RSV administered to HFDfed SIRT1 KD mice resulted in 5.8\% lower weight compared with the SIRT1 KD mice with HFD at day 30. Meanwhile, mice treated with RSV weighed less than the corresponding nonRSV-treated groups. Furthermore, liver weight was elevated in the HFD-fed SIRT1 KD mice compared with the HFD-fed WT mice, while these were altered by RSV supplementation (Fig. 1C). Food intake per day did not differ among groups during experiment (Fig. S1A). And it was showed that RSV administration led to an obvious increment in plasma RSV content (Fig. S1B). HFD feeding of WT and SIRT1 KD mice significantly altered the plasma and hepatic lipid profiles of TG, T-CHO, HDL-C, and LDL-C compared with HFD-fed mice (Fig. 1DG). Moreover, RSV-induced alterations of lipid profiles were notably abolished by SIRT1 KD, implying that SIRT1 plays a critical role in the amelioration of lipid metabolism alterations via RSV supplementation (Fig. 1D-G). Electron microscopy showed that RSV administered to HFD-fed WT mice resulted in fewer and smaller liver LDs compared with HFD-fed WT mice (Fig. 1H-K), suggesting an inhibitory effect of RSV on LD accumulation in the liver. As shown in Fig. $1 \mathrm{H}$ and I, the average diameter of LDs in RSV-treated WT mice was $0.91 \pm 0.01 \mu \mathrm{m}$, which was much smaller than that of the HFD group $(1.02 \pm 0.01 \mu \mathrm{m})$ and equivalent to an average reduction in LD volume of $29.2 \%$ following RSV administration. Consistent with the role of SIRT1 in the regulation of lipid profiles, SIRT1 KD mice with HFD showed significantly more and larger LDs compared with HFD-fed WT mice. The average diameters of the LDs were $2.52 \pm 0.02 \mu \mathrm{m}$ and $3.33 \pm 0.02 \mu \mathrm{m}$ in HFD-fed SIRT1 KD mice with and without RSV treatment, respectively (Fig. 1J and K). Furthermore, notable pathological changes such as increased hepatocyte hypertrophy, vacuolization, and inflammatory cell infiltration were observed in the liver tissue of WT mice given a HFD compared with mice fed a chow diet, while RSV administration remarkably ameliorated HFD-induced hepatic steatosis (Fig. $1 \mathrm{~L}$ and M). Furthermore, the benefits of RSV on liver pathophysiology were significantly abolished by KD of SIRT1 in SIRT1 KD mice (Fig. 1L and M). Overall, these results suggest that RSV administration protects against HFD-induced hepatic steatosis, specifically by reducing the accumulation of LDs in the liver. In addition, SIRT1 KD in vivo remarkably abrogated the benefits induced by RSV, implying that SIRT1 is involved in the amelioration of hepatic steatosis. 
Fig. 1. RSV $\mathrm{p} r$ ot e c t $s$ against HFDi n d u c e d $\mathrm{h}$ e $\mathrm{p}$ a $\mathrm{t} \mathrm{i} \mathrm{c}$ steatosis in mouse liver through SIRT1 (A) Male C57BL/6 mice (4-6 weeks old, $\mathrm{n}=5$ ) were initially fed a chow diet or HFD for 2 weeks. Thereafter, H F D - f e d mice were administrated with or without RSV of 400 $\mathrm{mg} / \mathrm{kg} / \mathrm{d}$ a y intragastrically for 30 days accompanied by the presence or absence of a pAAV-ZsGreenshRNA-mSIRT1 $\mathrm{p} \mathrm{l} \mathrm{a} \mathrm{s} \mathrm{m} \mathrm{i} \mathrm{d}$ in jection through nail vein every five days (arrowheads). (B) The body weight of d i f f e re $n t$ groups. (C) The liver weight of different groups. (D-E) The plasma (D) and the hepatic (E) triacylglyceride (TG) level was detected using a TG-content detection kit. (F-G) Plasma (F) and hepatic (G) lipid profiles of different groups. (H) Multilocular LDs (black arrows) were recognized by electron microscope. Scale bar, $4 \mu \mathrm{m}$. The LDs with the diameter of $0.5 \mu \mathrm{m}$ and above within one cell were measured and 15 cells were analyzed in each groups. (I) LD counting showed the quantity of LDs of different groups. (J) LD size distribution of different groups. (K) LD volume of different groups. (L) H\&E (hematoxylin and eosin) staining of liver samples of mice. Scale bar, $200 \mu \mathrm{m}$ (upper panel) and $50 \mu \mathrm{m}$ (lower panel). (M) Oil red 0 staining for liver sections. Scale bar, $200 \mu \mathrm{m}$ (upper panel) and $50 \mu \mathrm{m}$ (lower panel). Quantitative data are presented as mean $\pm \mathrm{SD}$, which represent at least three independent experiments. Data were presented as mean \pm SEM. ${ }^{*} \mathrm{P}<0.05,{ }^{* *} \mathrm{P}<0.01,{ }^{* * *} \mathrm{P}<0.001$, which denote statistical comparison between the two marked treatment groups. NS, no significance between the two marked groups. 
Fig. 2. RSV reduces LD accumulation in hepatocytes (AB) The primary hepatocytes and HepG2 cells (B) were treated with different doses 0.1 , $0.2,0.3,0.4$, or 0.5 $\mathrm{mM}$ ) of PA for 24 $h$ and cell viability was measured using a Cell Counting Kit-8 (CCK-8), respectively. (CD) The primary hepatocytes $(\mathrm{C})$ and HepG 2 cells (D) were treated as indicated and the intracellular TG content was detected using a TG content detection kit. (E) Cells were stained with Oil Red 0 and representative images were showed to visualize the LDs intracellularly. Scale bar, $50 \mu \mathrm{m}$. (F-G) The primary hepatocytes (F) and HepG2 cells (G) were treated with different concentrations (10, 20, 40 and $80 \mu \mathrm{M}$ ) of RSV for $24 \mathrm{~h}$, and the cell viability was measured by CCK8 assay. (H-I) The primary hepatocytes
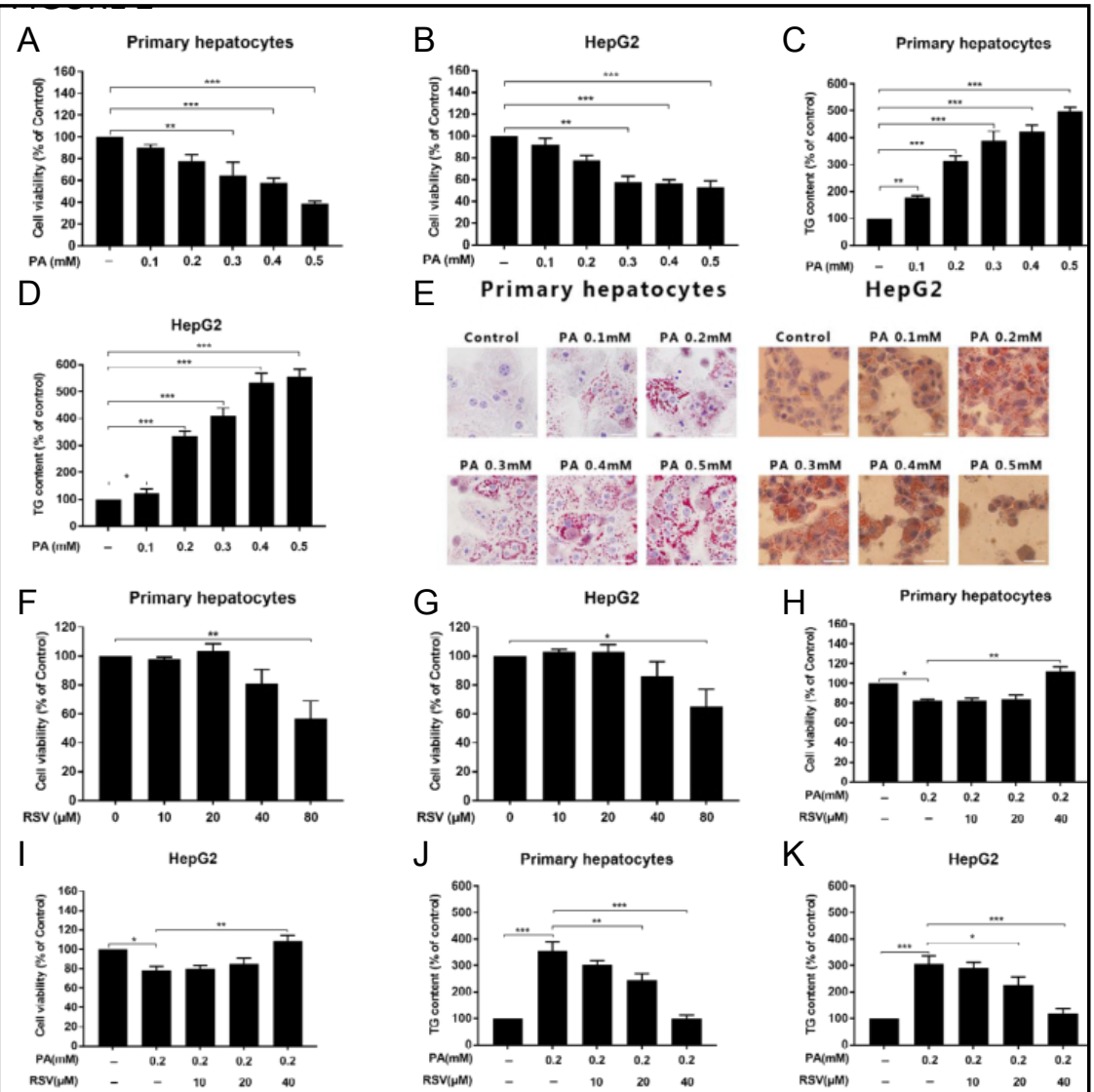

L

$$
\text { M }
$$
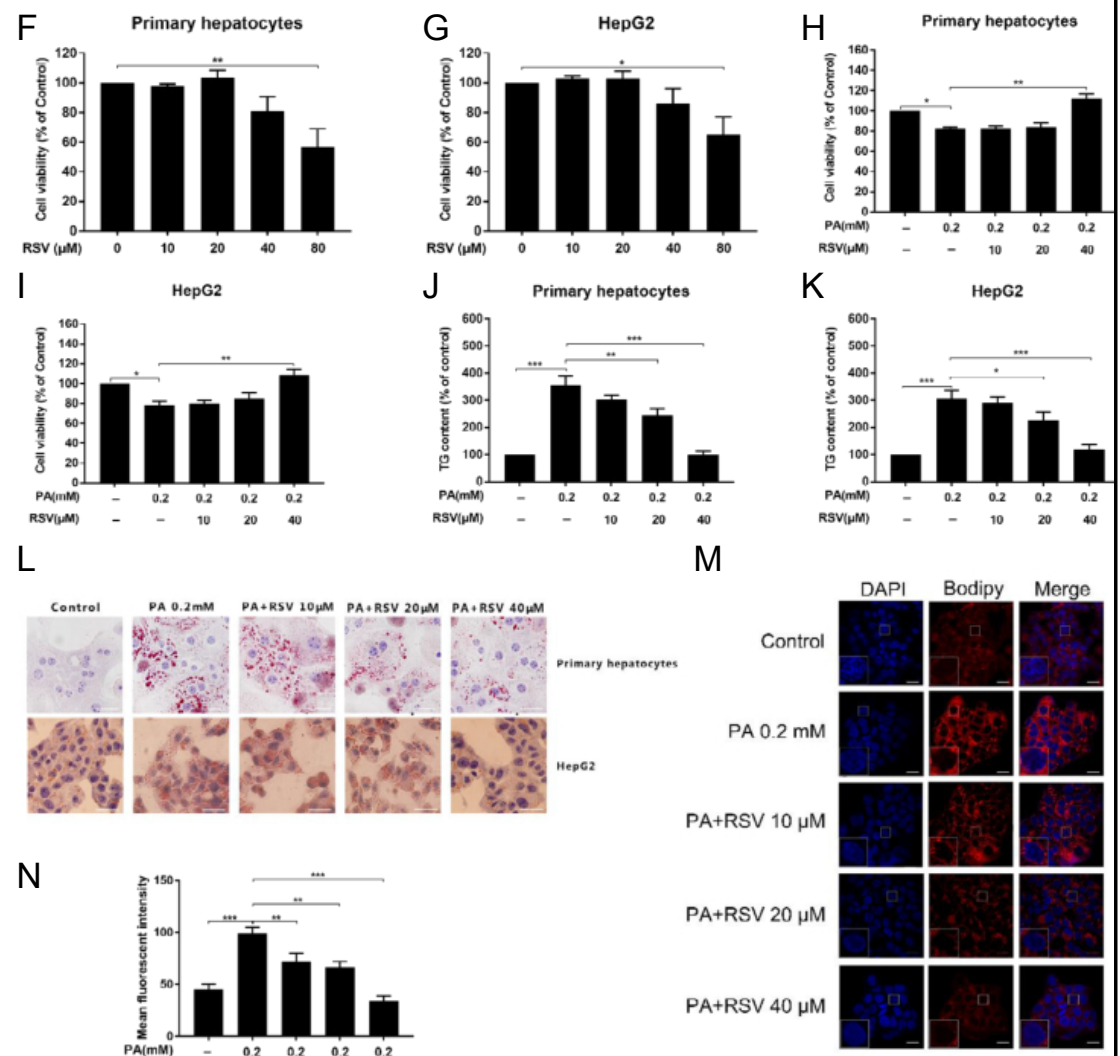

N
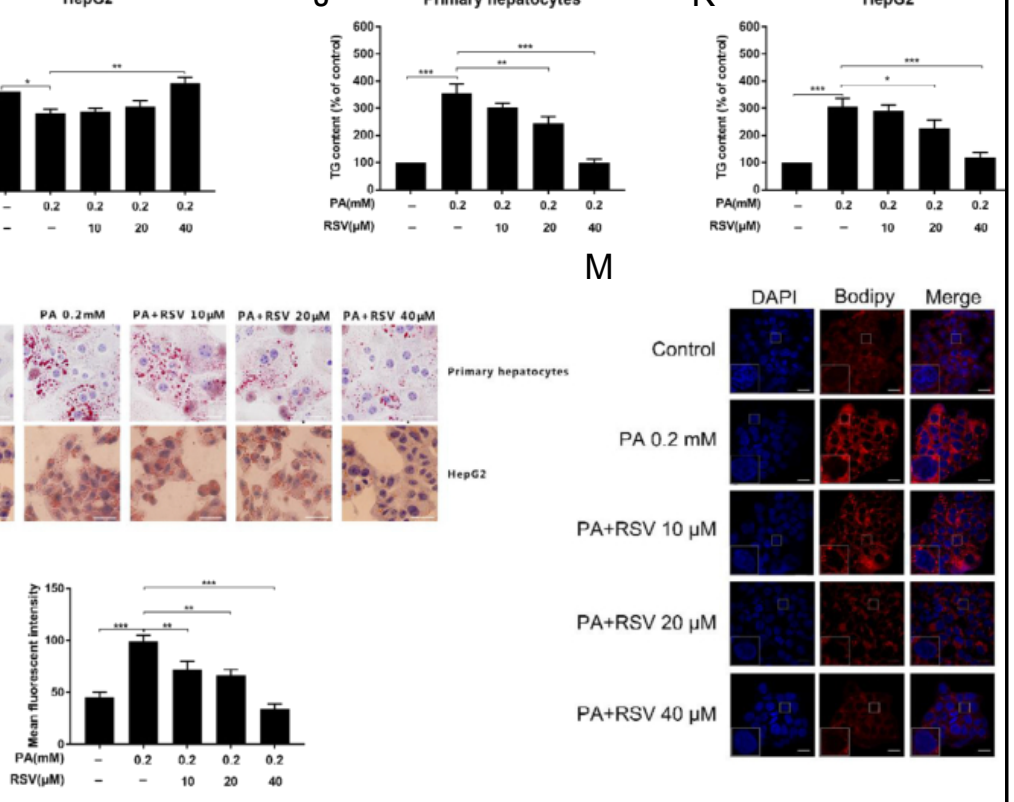

(H) and HepG2 cells

(I) were exposed to $0.2 \mathrm{mM}$ of PA for $24 \mathrm{~h}$, washed, and then were incubated with different concentrations $(10,20$ or $40 \mu \mathrm{M})$ of RSV. Cell viability was detected by CCK-8 assay. (J-K) The primary hepatocytes (J) and HepG2 cells $(\mathrm{K})$ were treated with $0.2 \mathrm{mM}$ of PA and were incubated with different concentrations of RSV. Intracellular TG content was detected with the corresponding assay kit. (L) Cells were stained with Oil Red 0 and representative images were showed to visualize the LDs intracellularly. Scale bar, $50 \mu \mathrm{m}$. (M) LDs were labeled with Bodipy 558/568 (Red) and the LD accumulation in HepG2 cells were visualized under a confocal microscopy using a $63 \times$ oil immersion objective. The inset shows a selected region that was magnified. Scale bar, $20 \mu \mathrm{m}$. (N) The mean fluorescent intensity was measured. Data were presented as mean \pm SEM. ${ }^{*} \mathrm{P}<0.05,{ }^{*} \mathrm{P}<0.01,{ }^{* * *} \mathrm{P}<0.001$, which denote statistical comparison between the two marked treatment groups. NS, no significance between the two marked groups. 


\section{Cellular Physiology Cell Physiol Biochem 2018;51:2397-2420 and Biochemistry Published online: 8 December 2018 \begin{tabular}{l|l} 
DOI: 10.1159/000495898 2018 The Author(s). Published by S. Karger AG, Basel \\
www.karger.com/cpb
\end{tabular} \\ Zhou et al.: Resveratrol Ameliorates LDs Through SIRT1/ATF6}

\section{$R S V$ reduces $L D$ accumulation in hepatocytes}

The cell hepatic steatosis model was established by utilization of PA as described previously [37]. At concentrations of up to $0.3 \mathrm{mM}$, PA significantly decreased viability in primary hepatocytes (Fig. 2A) and HepG2 cells (Fig. 2B), which was accompanied by increased intracellular TG content (Fig. 2C and D) and lipid accumulation (Fig. 2E) in a dose-dependent manner. Thus, $0.2 \mathrm{mM}$ of PA was used in subsequent experiments to achieve maximal lipid accumulation without cytotoxicity. The primary hepatocytes and HepG2 cells were treated with various concentrations $(10,20,40$, and $80 \mu \mathrm{M})$ of RSV alone for $24 \mathrm{~h}$. It was shown that $80 \mu \mathrm{M}$ of RSV has strong cytotoxic effects in both primary hepatocytes (Fig. 2F) and HepG2 cells (Fig. 2G). Thereafter, cells were pretreated with $0.2 \mathrm{mM}$ of PA for $24 \mathrm{~h}$, and then treated with various concentrations $(10,20$, and $40 \mu \mathrm{M})$ of RSV for an additional $24 \mathrm{~h}$. Treatment with RSV at concentrations of greater than $40 \mu \mathrm{M}$ notably increased the viability of PAinduced primary hepatocytes (Fig. 2H) and HepG2 cells (Fig. 2I). RSV treatment reduced the amounts of TGs in PA-induced primary hepatocytes (Fig. 2J) and HepG2 cells (Fig. 2K) in a dose-dependent manner. In addition, RSV treatment resulted in less accumulation of LDs compared with the PA-treated cells, as measured by Oil Red O (Fig. 2L) and Bodipy staining (Fig. $2 \mathrm{M}$ and $\mathrm{N}$ ). Thus, $40 \mu \mathrm{M}$ of RSV was used for the subsequent experiments. Taken together, these findings reveal that RSV treatment can decrease the accumulation of LDs in PA-induced hepatocytes.

\section{$R S V$ inhibits the expression of LD-associated genes}

RSV ameliorated hepatic steatosis in HFD-fed mice and reduced the accumulation of LDs in PA-induced hepatocytes; thus, we next explored the effect of RSV on the expression of LD-associated genes. We found that HFD reduced the expression levels of SIRT1 mRNA and protein in liver tissues of WT mice, and this effect was inhibited by RSV administration (Fig. $3 \mathrm{~A}-\mathrm{C}$ ). We also examined the expression levels of certain LD-associated genes in the liver tissues. Consistent with the previous study, Fsp27 $\beta$ mRNA and protein expression levels of in liver tissues were remarkably increased in HFD-fed WT mice, and this was attenuated by RSV administration (Fig. 3A-C)[38]. KD of SIRT1 enforced the expression of Fsp27 $\beta$ in HFD-fed SIRT1 KD mice, measured by gene expression assessment and intracellular immunofluorescence staining (Fig. 3A-E), implying that SIRT1 has an important role in the RSV-induced regulation of Fsp27 $\beta$ expression. In addition, the mRNA and protein expression levels of LD-associated genes such as ATF6, CREBH and PLIN1, which were strongly associated with hepatic LD accumulation and hepatic steatosis, were measured. The expression levels of the indicated genes were markedly upregulated in HFD-fed WT mice and inhibited by RSV administration (Fig. 3A-C). However, SIRT1 KD in SIRT1 KD mice led to significantly increased mRNA and protein expression levels among the indicated genes, suggesting a critical role of SIRT1 in the effects of RSV on the accumulation of LDs (Fig. 3A-C). Moreover, Bodipy staining (Fig. 2D and E) showed that the Fsp27 $\beta$ signal was much stronger in the SIRT1 KD group than in the WT group, indicating that SIRT1 can directly affect the levels of Fsp27 $\beta$, which is essential for the accumulation of LDs in the liver. We further investigated the effects of RSV on the expression levels of the LD-associated genes in primary hepatocytes and HepG 2 cells. We found that RSV treatment markedly suppressed the PA-induced downregulation of SIRT1 activity in a dose-dependent manner in primary hepatocytes (Fig. 3F) and HepG2 cells (Fig. 3G). Consistent with the enhanced activity of SIRT1 via RSV treatment, the mRNA and protein levels of SIRT1 were also increased by RSV treatment in primary hepatocytes and HepG2 cells (Fig. 3H-K). However, reduced expression of CIDEC in HepG2 cells and Fsp $27 \beta$ in primary hepatocytes was observed after RSV treatment compared with cells treated with PA alone, as measured by western blotting (Fig. 3H-L). Furthermore, the reduced intracellular expression of Fsp27 $\beta$ after RSV treatment was further confirmed by immunofluorescence cytochemistry assay (Fig. 3M-N). The mRNA and protein expression levels of LD-associated genes ATF6, CREBH, and PLIN1 were notably upregulated in PA- 
Fig. 3. RSV inhibits the expression of LDassociated genes (A) The mRNA expressions of SIRT1, ATF6, PLIN1, CREBH and Fsp27 $\beta$ in the liver of WT and SIRT1 KD mice by qRT-PCR assay. (B) The protein levels of SIRT1, ATF6, PLIN1, CREBH and Fsp27 $\beta$ in WT and SIRT1 KD mice were measured by western blotting assay. Actin was used as a loading control. (C) Bar charts showed the quantification of the indicated proteins. (D) The liver tissue were double-stained with anti-Fsp27 $\beta$ (green) antibody and Bodipy (Red), and were visualized under confocal m i cros copy using a 63x oil immersion
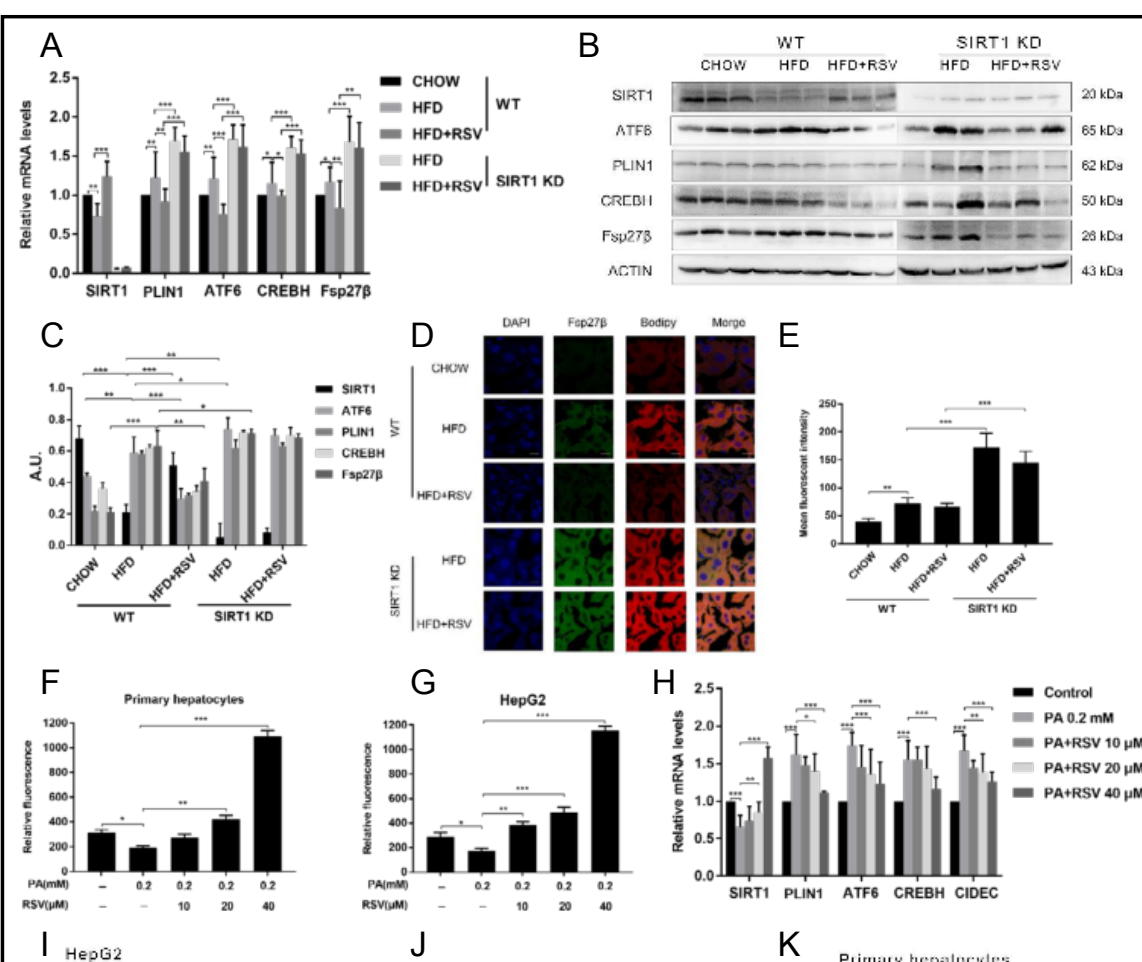

E

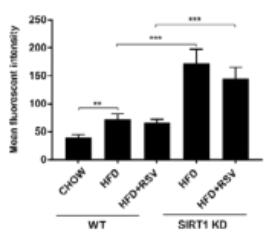

$\mathrm{H}_{2.5}$

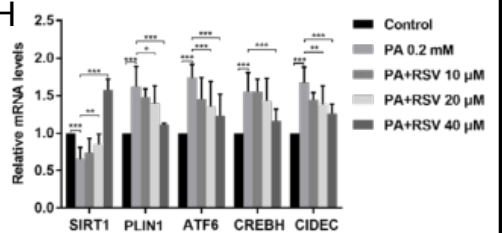

$\mathrm{J}$

K Primary hepaltucyles

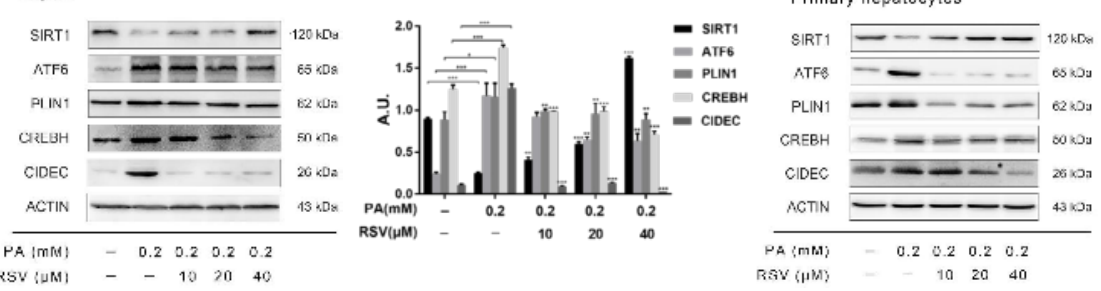
RSV \{UM] - $\quad 102040$

L M
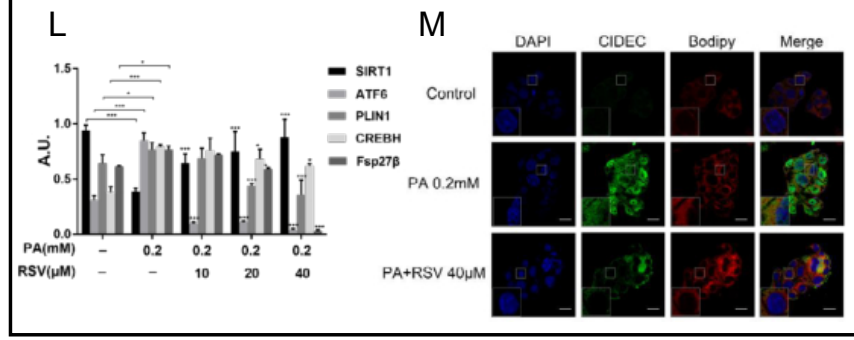

$\mathrm{N}$

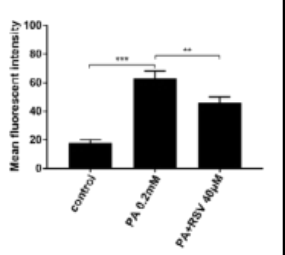

objective. Scale

bar, $20 \mu \mathrm{m}$. (E) The mean fluorescent intensity was measured. (F-G) The primary hepatocytes (F) and HepG2 cells $(G)$ were cultured with $0.2 \mathrm{mM}$ of PA for $24 \mathrm{~h}$ and then incubated with different concentrations $(10,20$ and $40 \mu \mathrm{M}$ ) of RSV for an additional $24 \mathrm{~h}$. SIRT1 activity was measured using a detection kit. (H) The relative mRNA expression levels of SIRT1, ATF6, PLIN1, CREBH and CIDEC in HepG2 cells were measured by qRTPCR assay. (I) The protein expressions of SIRT1, ATF6, PLIN1, CREBH and CIDEC in the HepG2 cells were measured by western blotting. (J) Bar charts showed the quantification of the indicated proteins. (K) The protein expressions of SIRT1, ATF6, PLIN1, CREBH and CIDEC in the primary hepatocytes were measured by western blotting assay. (L) Bar charts showed the quantification of the indicated proteins. (M) Intracellular LDs were double-stained with anti-CIDEC (green) antibody and Bodipy (Red) for immunofluorescence analysis. The inset shows a selected region that was magnified. Scale bar, $20 \mu \mathrm{m}$. (N) The mean fluorescent intensity was measured. Data were presented as mean $\pm \mathrm{SEM}$. ${ }^{*} \mathrm{P}<0.05,{ }^{* *} \mathrm{P}<0.01,{ }^{* * *} \mathrm{P}<0.001$, which denote statistical comparison between the two marked treatment groups or compared to the PA-treated group with the same color showed in the bar chart. 
Fig. 4. RSV suppresses LD accumulation and L D - a s s o c i a te d genes expression in hepatocytes through SIRT1 (A) The HepG2 cells were transfected with the siRNA for SIRT1 (SISIRT1) or its corresponding control siRNA (siNC), and then incubated with PA $\quad\left(\begin{array}{ll}0.2 & \mathrm{mM}\end{array}\right)$ followed by RSV $(40 \mu \mathrm{M})$ treatment. The intracellular TG content was detected using a TG-content detection kit. (B) LD accumulation in HepG2 cells was visualized under a confocal microscopy using a $63 \times$ oil immersion objective. The inset shows a selected region that was magnified. Scale bar, $20 \mu \mathrm{m}$. (C) The mean fluorescent intensity was measured. (D) The multilocular LDs (black arrows) were recognized by
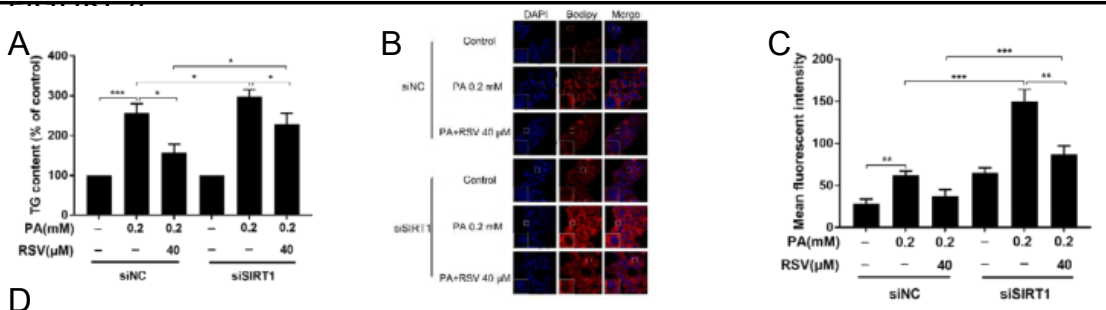
SINC $\quad$ SISIRT1
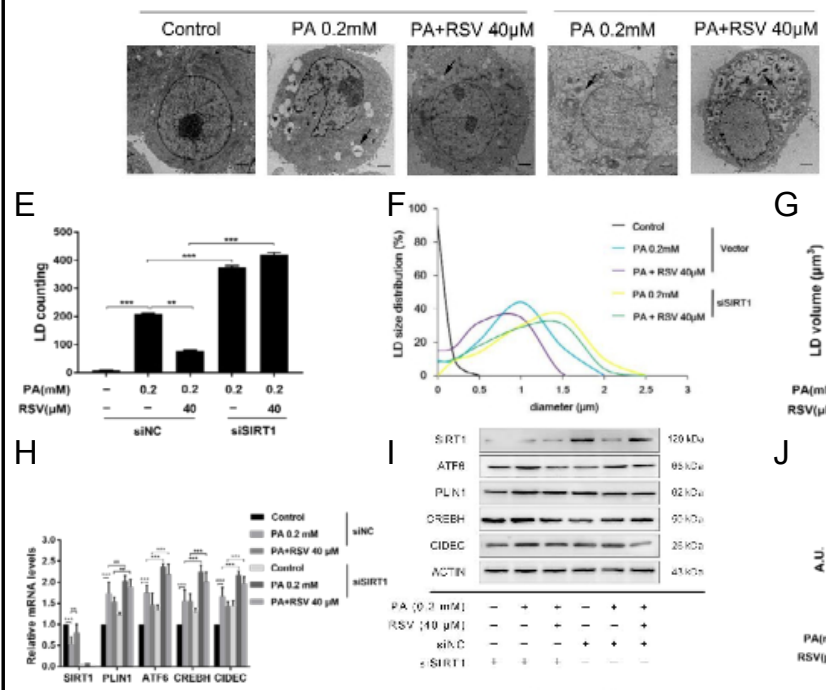

G
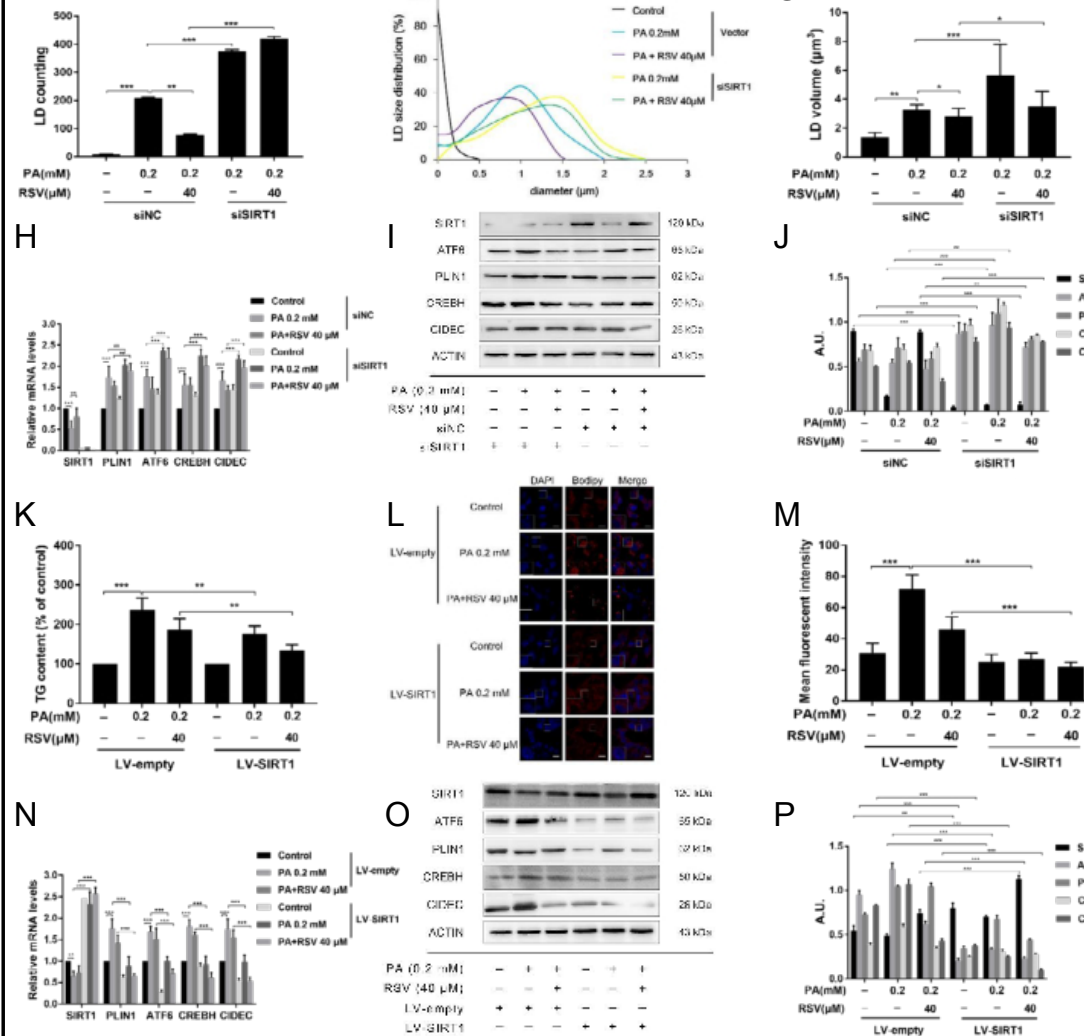
PLK - PLE:

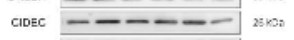

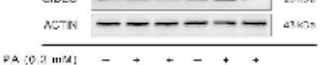

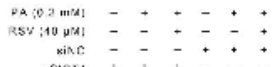

$J$

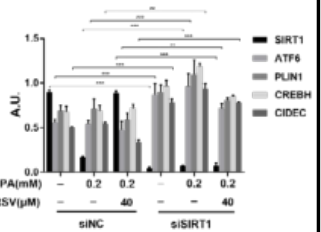

M

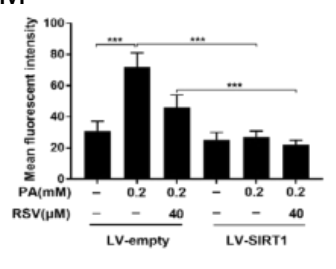

$\mathrm{P}$

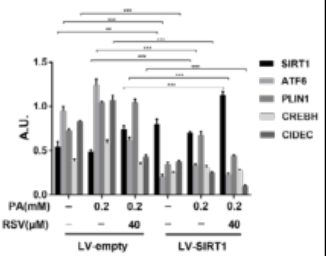
electron microscope.

Scale bar, $2 \mu \mathrm{m}$. The LDs with the diameter of $0.5 \mu \mathrm{m}$ and above within one cell were measured and 15 cells were analyzed in each groups. (E) LD counting showed the quantity of LDs of different groups. (F) LD size distribution of different groups. (G) LD volume of different groups. (H) The relative mRNA expression levels of the indicated genes in HepG2 cells were measured by qRT-PCR. (I) The protein expression of the indicated proteins in HepG2 cells by western blotting assay. Actin was used as a loading control. (J) Bar charts showed the quantification of the indicated proteins. (K) A lentiviral vector for SIRT1 (LV-SIRT1) or its corresponding empty vector were transfected to HepG2 cells and the hepatic TG contents were measured. (L) The LD accumulation in HepG2 cells were visualized under a confocal microscopy using a $63 \times$ oil immersion objective. The inset shows a selected region that was magnified. Scale bar, $20 \mu \mathrm{m}$. (M) The mean fluorescent intensity was measured. (N) The relative mRNA levels of the indicated genes in HepG2 cells were measured by qRT-PCR. (O) The protein expressions of the indicated genes in HepG2 cells were measured by western blotting assay. Actin was used as a loading control. (P) Bar charts showed the quantification of the indicated proteins. Data were presented as mean \pm SEM. ${ }^{*} \mathrm{P}<0.05,{ }^{* *} \mathrm{P}<0.01,{ }^{* * *} \mathrm{P}<0.001$, which denote statistical comparison between the two marked treatment groups. 


\section{Cellular Physiology Cell Physiol Biochem 2018;51:2397-2420

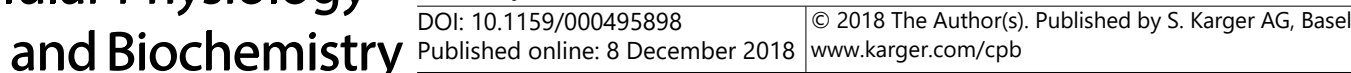 \\ Zhou et al.: Resveratrol Ameliorates LDs Through SIRT1/ATF6}

treated cells and dramatically inhibited by RSV treatment (Fig. 3H-L). Taken together, these data indicate that the inhibitory effect of RSV on LD accumulation might be associated with the inhibited expression of LD-associated genes.

\section{RSV suppresses LD accumulation and LD-associated genes expression in hepatocytes} through SIRT1

We next validated the involvement of SIRT1 in the RSV-induced inhibition of LD accumulation and LD-associated gene expression in HepG2 cells by silencing SIRT1 using a lipofectamine-based siRNA delivery system or lentiviral-mediated SIRT1

overexpression, respectively. Transfection of SIRT1 siRNA resulted in substantial KD of SIRT1 (90\% KD efficiency, data not shown). RSV treatment significantly suppressed the PAinduced elevation of TG content (Fig. 4A) and LD accumulation (Fig. 4B and C) in HepG2 cells, which was demonstrated by fewer and smaller intracellular LDs (Fig. 4D-G), whereas these benefits were notably abrogated by SIRT1 silencing. These findings indicate that SIRT1 plays a critical role in the RSV-induced inhibition of lipid accumulation and LD formation in HepG2 cells. Next, the mRNA and protein expression levels of genes involved in the accumulation of LDs, including ATF6, CREBH, CIDEC, and PLIN1 (Fig. 4H-J), were detected. The mRNA

and protein expression levels of the indicated genes were elevated in PA-induced HepG2 cells, and these changes were inhibited by RSV treatment. However, RSV-induced alterations of the indicated genes expression were eliminated by SIRT1 silencing. Furthermore, to test whether the expression of SIRT1 was sufficient to reduce LD accumulation, we then introduced LV-SIRT1 and corresponding LV-empty into HepG2 cells. We found that enforced SIRT1 expression markedly attenuated the rise in TG content and the accumulation of LDs in PA-induced HepG2 cells (Fig. 4K-M). Moreover, RSV treatment resulted in even lower amounts of TG and LD accumulation in PA-treated cells compared with cells with the LV-empty vector (Fig. 4K-M). When we introduced the LV-SIRT1 vector into HepG2 cells, the mRNA level of SIRT1 increased by as much as approximately 2.5 -fold compared with the LV-empty group (Fig. 4N). Obvious reductions in the expression levels of LD-associated genes, including ATF6, CREBH, CIDEC, and PLIN1, were observed after transfection with the LV-SIRT1 vector in the PA-induced HepG2 cells compared with cells transfected with the corresponding LVempty vector (Fig. 4N-P). RSV treatment resulted in much lower expression of the indicated genes in PA-treated cells compared with cells with the LV-empty vector (Fig. 4N-P). These data indicate that SIRT1 is heavily involved in the regulation of LD accumulation after RSV treatment.

\section{ATF6 is involved in RSV-induced inhibition of LD accumulation in hepatocytes}

ATF6 has emerged as a novel metabolic regulator of the cellular signals that regulate lipid storage and hepatic steatosis. Previous findings indicated that the effect of RSV on the expression of SIRT1 in both liver tissues and HepG2 cells correlated inversely with that on ATF6 (Fig. 3A, 4I, and 40); thus, we hypothesized that ATP6 might be involved in the RSV-induced regulation of LD accumulation in the liver. To verify the role of ATF6 in the modulation of LD accumulation following RSV treatment, ATF6 siRNA was used to silence ATF6 in HepG2 cells. There were obvious lower levels of TG and LD accumulation in RSVinduced HepG2 cells transfected with ATF6 siRNA compared with cells transfected with the corresponding control siRNA, suggesting that ATF6 is strongly involved in the RSVinduced inhibition of LD accumulation (Fig. 5A-C). Silencing of ATF6 resulted in significantly enhanced mRNA and protein expression levels of SIRT1 in RSV-induced HepG2 cells, implying that ATF6 might be a negative modulator of SIRT1 expression in RSV-induced HepG2 cells (Fig. 5D-F). Silencing of ATF6 also led to a down-regulation of LD-associated genes including CREBH, CIDEC, and PLIN1 in RSV-induced HepG2 cells, suggesting that ATF6 has a critical role in the regulation of LD-associated genes following RSV treatment (Fig. 5DF). Moreover, HepG2 cells were transfected with a p3×FLAG-ATF6 plasmid to further test whether the inhibitory effect of lipid accumulation in hepatocytes after RSV treatment could be hampered by the overexpression of ATF6. As expected, the RSV-induced reductions in TG 
Fig. 5. ATF6

is involved in

RSV-induced

i $n$ hibition

of

LD

accumulation in hepatocytes

(A) Cells were transfected with the siRNA for ATF6 or its corresponding control siRNA, and then were incubated with PA (0.2 mM) followed by RSV $(40 \mu \mathrm{M})$ treatment . Intracellular TG contents were detected using a TGc o n t e n t detection kit. (B) The LD accumulation in HepG2 cells were vi s u a li z ed under a c o n f o c a l microscopy using a $63 \times$ oil immersion objective. The inset shows a selected region that was magnified.
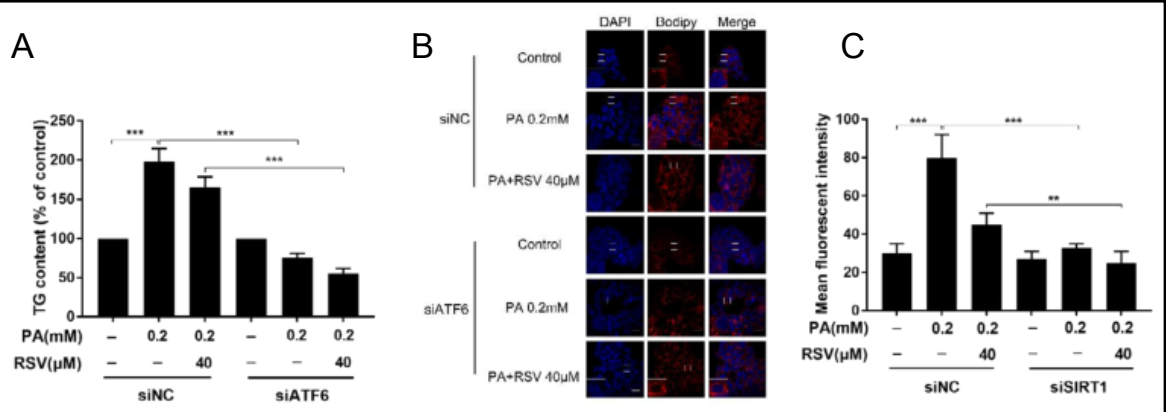

D

E

F
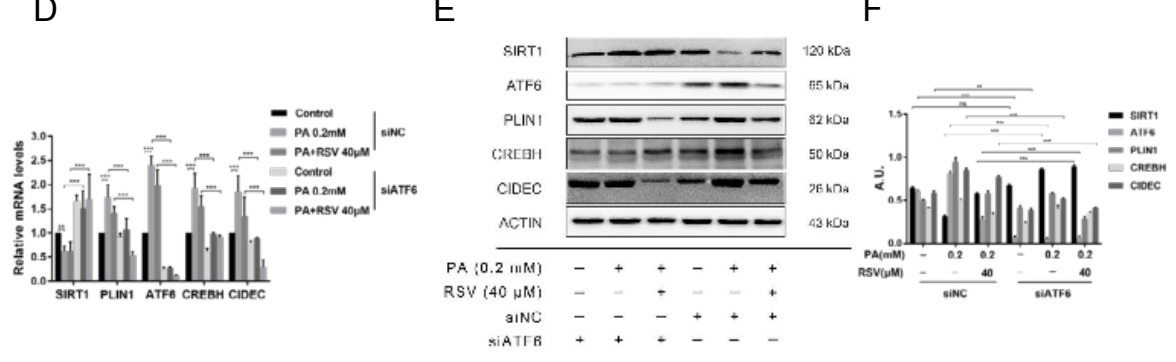

G

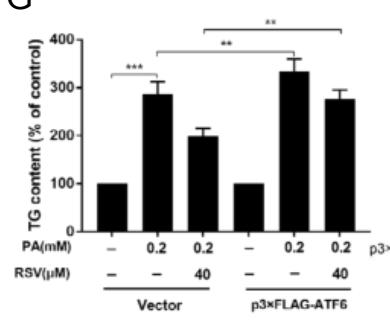

J

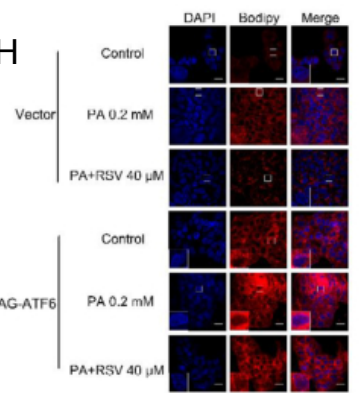

K
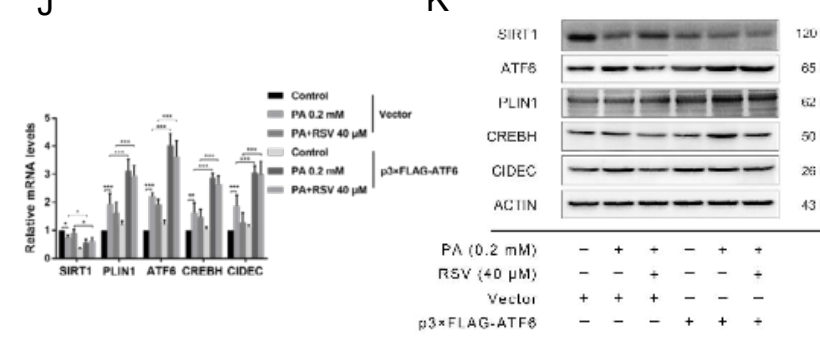

$\mathrm{L}$
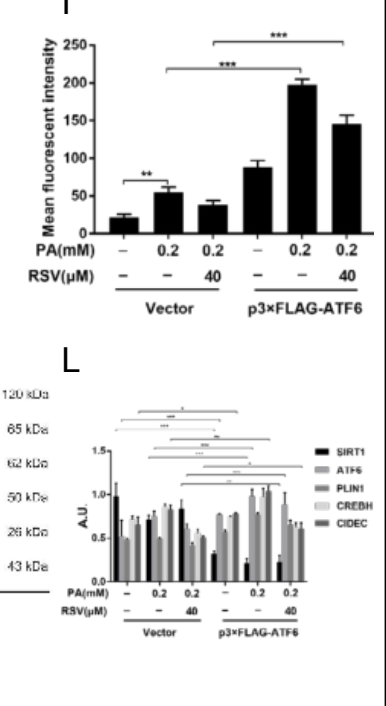

Scale bar, $20 \mu \mathrm{m}$. (C) The mean fluorescent intensity was measured. (D) The relative mRNA expression levels of the indicated genes in HepG2 cells were measured by qRT-PCR assay. (E) The proteins levels of the indicated proteins in HepG2 cells were detected by western blotting assay. Actin was used as a loading control. (F) Bar charts showed the quantification of the indicated proteins. (G) The HepG2 cells were transfected with a p3×FLAG-ATF6 plasmid or its corresponding control vector, and then incubated with PA $(0.2 \mathrm{mM})$ followed by RSV $(40 \mu \mathrm{M})$ treatment. The intracellular TG content was detected using a TG-content detection kit. (H) The LD accumulation in HepG2 cells was visualized under a confocal microscopy using a $63 \times$ oil immersion objective. The inset shows a selected region that was magnified. Scale bar, $20 \mu \mathrm{m}$. (I) The mean fluorescent intensity was measured. (J) The relative mRNA expressions of the indicated genes in HepG2 cells were detected by qRT-PCR. (K) The proteins levels of the indicated proteins in HepG2 cells were measured by western blotting. Actin was used as a loading control. (L) Bar charts showed the quantification of the indicated proteins. Data were presented as mean $\pm \mathrm{SEM}$. ${ }^{*} \mathrm{P}<0.05,{ }^{* *} \mathrm{P}<0.01,{ }^{* * *} \mathrm{P}<0.001$, which denote statistical comparison between the two marked treatment groups. 
Fig. 6. RSV stimulates SIRT1 by a positive feedback loop associated with ATF6 (A) The HepG2 cells were treated as indicated and the SIRT1 promoter activity

was detected by a dual-luciferase reporter assay. (B) A schematic representation of the human SIRT1 gene promoter showing the core promoter sequence for ChIP analysis. And the ChIP assay was performed to detect the direct binding of ATF6 to the SIRT1 promoter. The antibody against ATF6 was used for immuno precipitation of the chromatin DNA fragment, taking IgG as the negative control. The precipitated DNA was extracted and amplified by qRT-PCR. The input (total DNA extract) was used as a positive control. GAPDH primers were used as a negative control. (C) After the indicated treatment, the HepG2 cells were lysed with RIPA, and the lysates were subjected to immunoprecipitation using anti-IgG or anti-ATF6 antibodies as indicated. SIRT1 protein was immunoprecipitated. (D) After the indicated treatment, HepG2 cells were incubated with PLA antibodies and the cells were observed under a confocal microscopy ( $\times 63$ ). Each red dot represents a contacting-site between SIRT1 and ATF6. The nucleus was counterstained with DAPI. Magnification $63 \times$. (E) Acetylation of ATF6 after RSV exposure was determined by immunoprecipitation with an anti-ATF6 antibody, followed by the immunoblotting analysis with an acetylated-lysine antibody. (F) The results are expressed as a percentage of the control, which is set at $100 \%$. Data were presented as mean $\pm \mathrm{SD}$. ${ }^{*} \mathrm{P}<0.05,{ }^{* *} \mathrm{P}<0.01,{ }^{* * *} \mathrm{P}<0.001$, which denote statistical comparison between the two marked treatment groups.

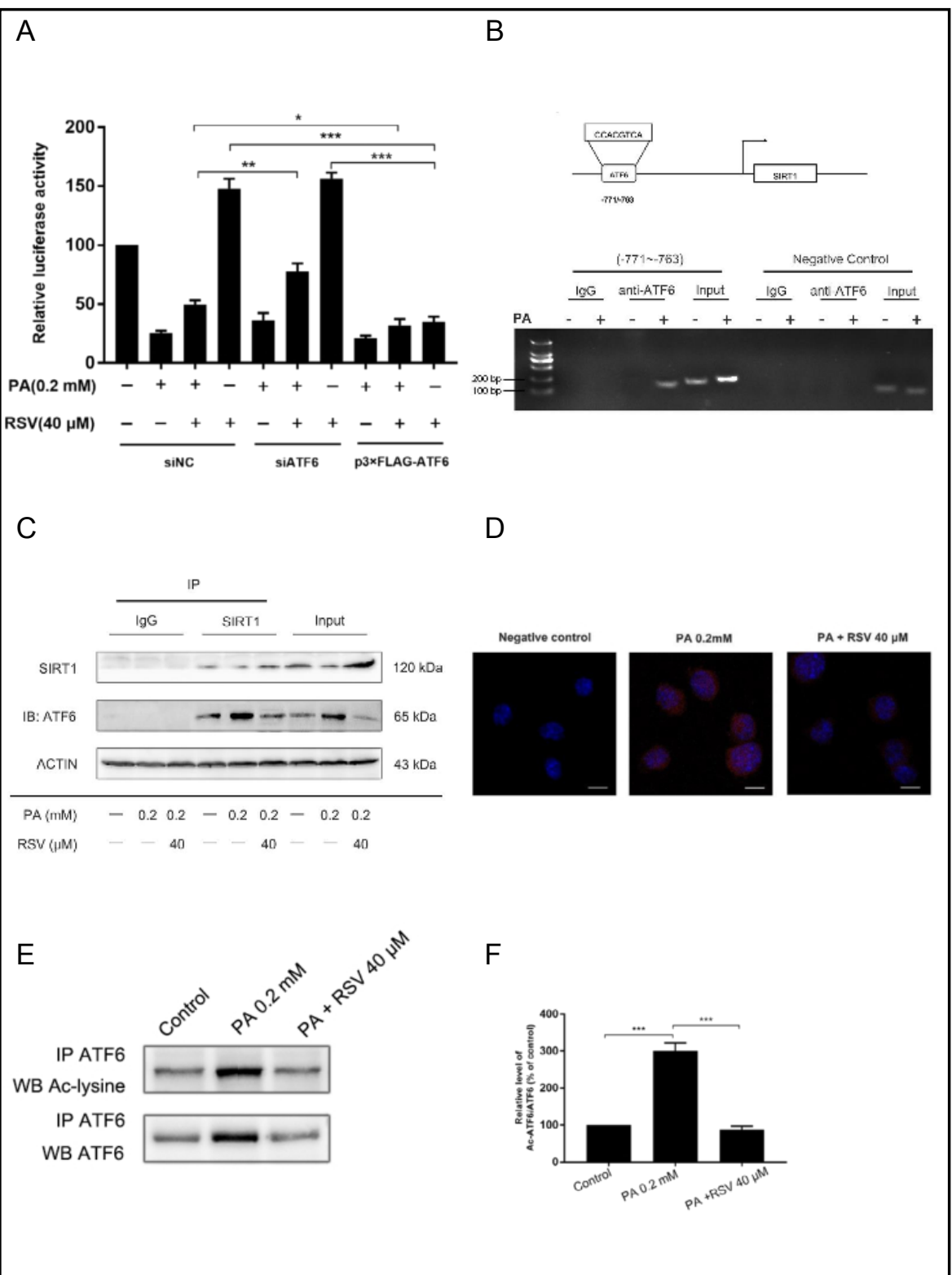




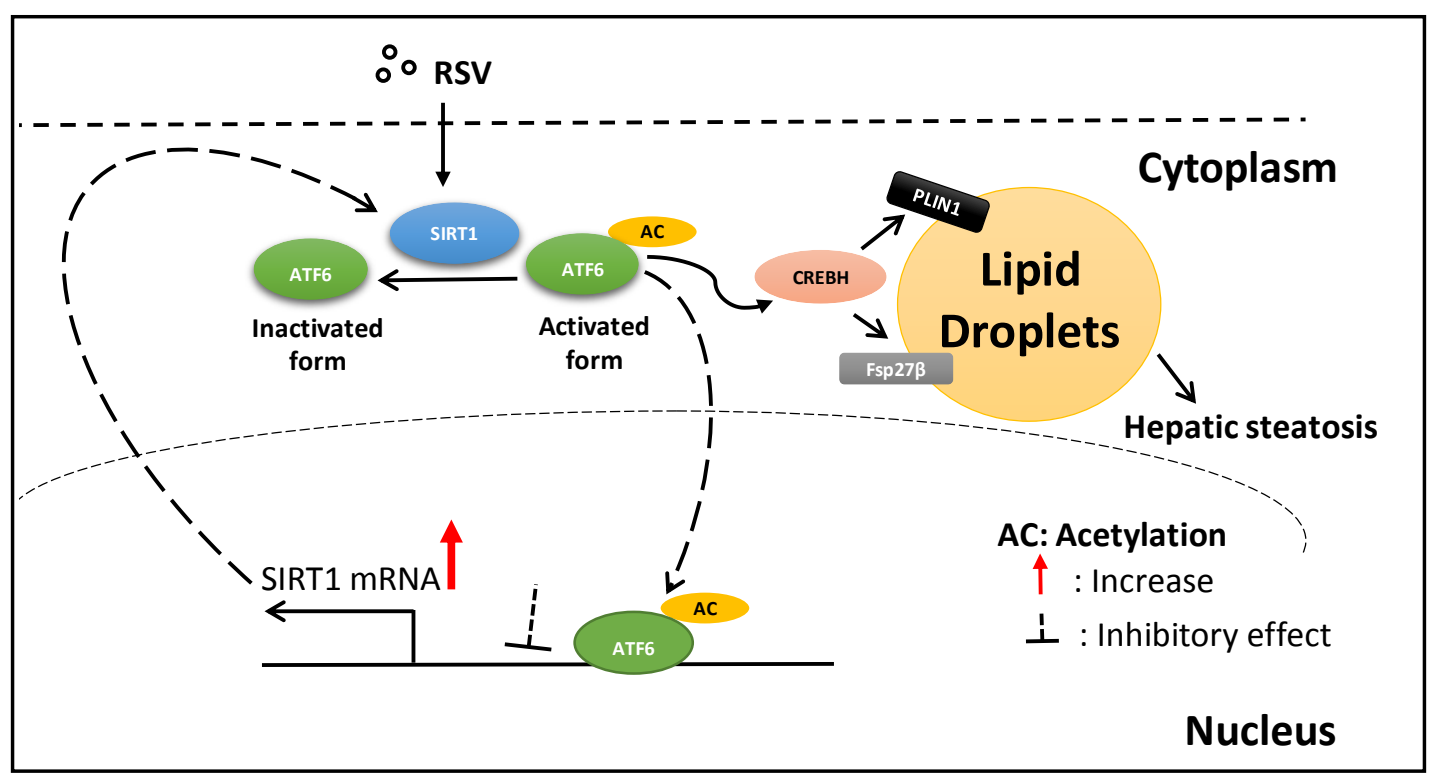

Fig. 7. Schematic illustration of the inhibitory effect of RSV on LD accumulation through SIRT1/ATF6dependent mechanism RSV dominantly attenuated hepatic steatosis and reduced LD accumulation in mouse liver and hepatocytes by inhibition of LD-associated genes, which was mediated through the stimulation of SIRT1, followed by the increased deacetylation and inactivation of ATF6, resulting in a positive feedback loop for SIRT1 transcription involved with ATF6 binding to the SIRT1 promoter region.

and the accumulation of LDs in HepG2 cells were weakened by the forced overexpression of ATF6 compared with cells with the control vector, implying that ATF6 overexpression can block RSV-induced benefits in the treatment of lipid accumulation (Fig. 5G I). Measured by western blotting and real-time RT-PCR assays, the ectopic expression of ATF6 notably also led to decreased expression of SIRT1 and increased expression of CREBH, CIDEC, and PLIN1 in HepG2 cells after RSV treatment (Fig. 5J-L). These results indicate that ATF6 is crucial for RSV-induced inhibition of LD accumulation in hepatocytes, and the RSV-induced regulation of SIRT1 and certain LD-associated genes are associated with ATF6.

\section{RSV stimulates SIRT1 by a positive feedback loop associated with ATF6}

We next explored the potential interplay between SIRT1 and ATF6 in hepatocytes after RSV treatment. To identify whether ATF6 might modulate the transcription process of SIRT1, HepG2 cells were transfected with a pGL3-Basic-SIRT1 plasmid with firefly luciferase activity, followed by co-transfection with a siRNA for ATF 6 or a p3×FLAG-ATF6 plasmid and a pRL-TK plasmid. Through the dual-luciferase assay, it was revealed that ATF6 silencing dramatically intensified RSV-induced SIRT1 transcriptional activity, whereas overexpression of ATF6 led to the suppression of SIRT1 transcriptional activity (Fig. 6A). By analyzing the SIRT1 promoter sequence with bioinformatics software, as described above, one putative binding site of ATF6 was identified within the 771 to $763 \mathrm{bp}$ region of the SIRT1 promoter (Fig. 6B). We performed a ChIP assay to confirm whether there is direct binding of ATF6 to the SIRT1 promoter. As shown in Fig. 6B, there was obvious enrichment of the binding site of ATF6 within the SIRT1 promoter region, indicating that the modulation of SIRT1 transcription in HepG2 cells is likely due to the direct binding of ATF6 to the SIRT1 gene promoter. Next, by endogenous Co-IP assay, it was found that RSV treatment enhanced the co-precipitation of ATF6 and SIRT1 in HeG2 cells, implying an enhanced interaction between ATF6 and SIRT1 (Fig. 6C). Furthermore, we carried out a PLA to identify whether RSV promoted a direct interaction between ATF6 and SIRT1 in RSV-treated HepG2 cells [35]. With specific antibodies for ATF6 and SIRT1, there were obvious red fluorescence spots scattered within the HepG2 cells, indicating a direct interaction between ATF6 and SIRT1. In 


\section{Cellular Physiology Cell Physiol Biochem 2018;51:2397-2420

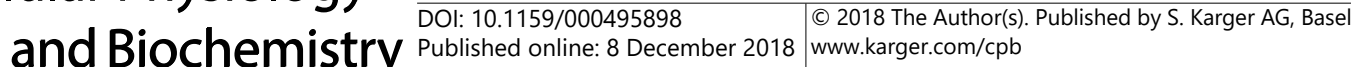 \\ Zhou et al.: Resveratrol Ameliorates LDs Through SIRT1/ATF6}

the presence of RSV, the number of red fluorescence spots in HepG2 cells was significantly greater than with PA alone, implying that RSV stimulates the interaction between ATF6 and SIRT1 (Fig. 6D). Since SIRT1 is the histone deacetylase SIR2 in Caenorhabditis elegans, we tested whether SIRT1 regulated ATF6 deacetylation. We measured ATF6 acetylation levels with immunoprecipitation and subsequent western blotting using an anti-acetyl-lysine antibody (Fig. 6E and F). SIRT1 significantly decreased the acetylation levels of ATF6 by 3-fold compared with controls. These results demonstrate that SIRT1 can directly deacetylate ATF6 and prompted us to further determine whether ATF6 and SIRT1 co-localize and/or physically bind to each other. Taken together, these findings clearly indicate that RSV treatment leads to increased transcription of SIRT1 via the inhibition of ATF6, as well as deacetylation of ATF6 via SIRT1 in HepG2 cells.

\section{Discussion}

NAFLD is the most common spectrum of metabolic liver disease worldwide and its prevalence is increasing rapidly in adults and adolescents. NAFLD is considered to be the hepatic manifestation of metabolic syndrome, and it is commonly associated with type 2 diabetes, obesity, and dyslipidemia. The management of NAFLD has traditionally depended on treating underlying comorbidities because there is no medication indicated for the treatment of NAFLD itself. In this study, we found for the first time that RSV strongly attenuated hepatic steatosis and reduced the accumulation of LDs in mouse liver and hepatocytes. The benefits might be mediated by the inhibition of LD-associated genes through the stimulation of SIRT1. RSV treatment led to increased deacetylation and inactivation of ATF6, which directly binds to the SIRT1 promoter region and inhibits SIRT1 transcription, resulting in a positive feedback loop for the expression of SIRT1.

NAFLD is defined as a systemic, multifactorial disease involving multiple organs, such as adipose tissue, muscle, and intestines [39]. The underlying mechanism for the development and progression of NAFLD is complex and multifactorial. Different theories have been formulated-the "two-hit" hypothesis is the prevailing theory for the development of NAFLD. According to the theory, hepatic accumulation of lipids secondary to a sedentary lifestyle, a HFD, obesity, and IR acts as the first hit, sensitizing the liver to further insults, which act as the "second hit" and further activate inflammatory cascades and fibrogenesis. Recently, LDs have been recognized as dynamic organelles involved in multiple cellular processes. In particular, the excess lipids in hepatic steatosis are primarily neutral lipids, for example, TG and cholesterol esters, and are stored in dynamic organelles called LDs of hepatocytes and other liver cells (for example, hepatic stellate cells and Kupffer cells). In essence, NAFLD results from an imbalance between the influx of FAs to the liver from the diet, adipose tissue lipolysis, or de novo lipogenesis [40]. FAs from peripheral adipose stores are estimated to contribute to approximately $60 \%$ of the TGs stored in hepatocytes in patients with NAFLD [41], and these increase substrate availability for LD formation. Unbalanced storage and utilization of LDs further leads to supraphysiological TG accumulation in hepatocytes, known as hepatic steatosis [6]. In this study, we found that HFD feeding could induce hepatic steatosis in the mouse liver, in addition to notable amounts of $\mathrm{LD}$ accumulation. $\mathrm{LD}$ accumulation was also observed in PA-induced primary hepatocytes and HepG2 cells in vitro. As expected, HFD and PA-induced accumulation of LD in livers and hepatocytes were significantly ameliorated by RSV treatment, suggesting that it is beneficial for the inhibition of LD accumulation in liver and hepatocytes. This is supported by the finding from Tang and colleagues [42]. Furthermore, we detected the effect of RSV on the expression of certain LD-associated genes. Numerous LDassociated genes have been implicated in the development of hepatic steatosis. Among them, CIDE proteins constitute an area of active research with regard to LD accumulation and hepatic steatosis and are the most well studied. Fsp27 $\beta / C I D E C$ belongs to the CIDE family, which includes three members (CIDE A, B, and C) and shares homology with the DNA fragmentation factor DEF40/45 at the N-terminal region [40]. Previous studies 


\section{Cellular Physiology Cell Physiol Biochem 2018;51:2397-2420 and Biochemistry \begin{tabular}{l|l} 
DOl: 10.1159/000495898 & (c) 2018 The Author(s). Published by S. Karger AG, Basel \\
www.karger.com/cpb
\end{tabular} \\ Zhou et al.: Resveratrol Ameliorates LDs Through SIRT1/ATF6}

have revealed that CIDE C expression in the liver is upregulated in obese mice and associated with increased TG storage in hepatocytes $[43,44]$. Fsp27 $\beta$ deficiency mice fed a HFD are resistant to obesity and hepatic steatosis and these phenomena are strongly associated with increased energy expenditure [45]. Genetic manipulation of Fsp27 $\beta$ levels in cultured cells lead to alterations in the numbers and functions of mitochondria such as lipogenesis/ lipolysis, $\beta$-oxidation, and even cell identities [46]. Moreover, transient suppression of Fsp27 $\beta$ expression in $o b / o b$ mouse livers by shRNA-expressing adenovirus remarkably attenuates NAFLD, especially around the portal areas [45]. These findings indicate that Fsp27 $\beta$ is also a key regulator in promoting larger LDs, steatosis, and the pathogenesis of NAFLD. We found that RSV decreased the expression of Fsp27 $\beta /$ CIDEC in the livers of HFD-fed mice. It has been demonstrated that Fsp $27 \beta$ is highly expressed in livers with steatosis and contributes to the accumulation of TGs, which are activated by CREBH through the binding of CREBH to its promoter [38]. CREBH is a liver-specific transcription factor and a UPR gene dependent on ATF6 $[18,47]$. Moreover, PLIN1 is normally found in adipocytes and is responsible for the coating of large LDs [48]. It interacts with Fsp27 $\beta /$ CIDEC and mediates the exchange of lipids between LDs [49]. It was found that PLIN1 is highly expressed in the liver during NAFLD, which implies that it plays a critical role in the development of NAFLD [50]. Thus, the accumulation of LDs in the liver might be correlated with the activation of some LD-associated genes like Fsp27 $\beta$ and PLIN1 in hepatocytes. It is reported that RSV can downregulate the activity of PLIN1 on adipocytes [51]. Our study suggests that RSV treatment can inhibit the accumulation of LDs by inhibiting the expression of Fsp27 $\beta$ and PLIN1 via inhibition of the ATF6/CREBH-mediated pathway. This finding also provides new targets for the prevention and treatment of NAFLD.

RSV (trans-3, 4', 5-trihydroxystilbene) is a polyphenolic compound found in many natural plant foods such as grapes (and red wine), strawberries, mulberries, and peanuts. It has been widely studied due to its multiple bioactivities, in particular its antioxidant and antitumor properties. The effects of RSV on glucose and lipid metabolism, such as in lowering blood lipids, improving insulin sensitivity, and glucose tolerance, have become the focus of research [52]. So far, considerable research on the therapeutic effects of RSV in NAFLD and other chronic liver diseases has been reviewed [53-56]. It has been demonstrated that RSV can reduce de novo FA synthesis and TG synthesis and promote FA oxidation, which is mediated through the activation of AMPK and SIRT1 $[55,57]$. Moreover, RSV can attenuate hepatic steatosis and inflammation in NASH or NAFLD animal models by regulating autophagy [58] and protecting against HFD-induced mitochondrial dysfunction in hepatocytes [59]. We found that RSV could improve hepatic steatosis through the activation of SIRT1-mediated LD accumulation. RSV is a well-known activator of SIRT1, and our previous study found that RSV partially mediated its effects via the SIRT1 signaling pathway in vitro and in vivo [25, 60]. In this study, SIRT1 KD mice fed a HFD had significant gains in body weight and the accumulation of hepatic lipids compared with the controls, demonstrating that SIRT1 is a key regulator in energy homeostasis and hepatic lipid metabolism. As expected, RSV treatment apparently restored SIRT1 levels in the livers of HFD-fed WT mice. On the other hand, RSV treatment simultaneously suppressed the expression of the indicated LD-associated genes including ATF6, CREBH, and Fsp27 $\beta$ in the livers of HFD-fed WT mice, leading to a remarkable suppression of body weight gain and hepatic lipid content, which is consistent with Andrade's report [61]. Therefore, RSV could decrease the expression of Fsp27 $\beta / C I D E C$ and other LDassociated genes in the liver and hepatocytes through the IRT1-mediated signaling pathway. The SIRT family comprises NAD-dependent histone deacetylases (HDACs), which consist of 7 mammalian proteins, SIRT 1-7 [62]. The SIRT family regulates protein function through posttranslational modifications including deacetylation, succinylation, and malonylation, and has a profound impact on carbohydrate and lipid metabolism. It has been found that NAFLD patients show decreased expression of SIRT1, SIRT3, SIRT5, and SIRT6 [63]. Our results suggest that RSV might attenuate hepatic steatosis, at least in part, by stimulating SIRT1 activity and upregulating SIRT1 expression. It is noteworthy that SIRT1 was knocked down rather than knocked out in mice via the systematic administration of shSIRT1. Thus, 


\section{Cellular Physiology Cell Physiol Biochem 2018;51:2397-2420

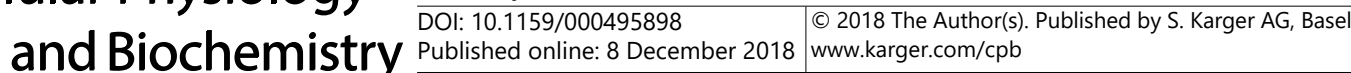 \\ Zhou et al.: Resveratrol Ameliorates LDs Through SIRT1/ATF6}

we must interpret the data cautiously because incomplete suppression of SIRT1 expression is likely to cause variations and inconsistent results. To further delineate the involvement of SIRT1 in RSV-mediated hepatic benefits, SIRT1 deficient mice and even liver-specific SIRT1 deficient mice would represent a better model

Increased LD formation can also contribute to hepatic steatosis, which occurs under a variety of circumstances. The activation of cell stress pathways generally increases the numbers of LDs forming in cells [64-66]. In mice, HFD leads to the formation of massive amounts of LDs in hepatocytes. These processes are often accompanied by the activation of ER stress [67], a known activator of a lipogenic gene expression program in the liver [68]. ER stress is a phenotypic hallmark in hepatic steatosis that can activate intramembrane proteolysis. Glucose regulated protein 78 (GRP78) plays a central role in the monitoring of cell homeostasis and during ER stress conditions and activates the adaptive process, termed the UPR. Under nonstress conditions, GRP78 binds to its client proteins protein kinase-like ER kinase, ATF6, and inositol-requiring enzyme 1, preventing their signaling. However, when the ER is overloaded with newly synthesized proteins or is "stressed" by agents that cause the accumulation of unfolded proteins, GRP78 binds to the unfolded proteins in the ER, freeing its client proteins $[69,70]$. The nuclear translocation of ATF6, the master transcription factor in the regulation of TG synthesis in hepatocytes, contributes to the storage of TG in the liver [71]. It has been demonstrated that the inhibition of HDAC can induce GRP78 acetylation, leading to therapeutic resistance, which is attenuated when GRP78 is knocked down using RNA interference [72]. A previous study demonstrated that lipid-accumulated HepG2 cells are susceptible to injury. RSV can improve the stressed cells, and this is partially mediated by restoring the function of the ER [73]. Thus, SIRT1, which is one of the HDACs, might regulate ATF6 partially via translational modification of GRP78. On the other hand, as a member of the ATF subfamily of the bZIP transcription factors [74], ATF6 has the potential to act as either a transcriptional activator or a transcriptional repressor. A previous study has shown that ATF6 confers a multidrug resistance phenotype to gastric cancer cells through the transactivation of SIRT1 expression [75]. We therefore assume that ATF6 might also have a transcriptional effect on SIRT1. The present study revealed that there is a positive feedback loop for SIRT1 expression that involves ATF6, because SIRT1 KD or overexpression in hepatocytes led to up-regulated or down-regulated expression of ATF6, whereas ATF6 silencing or overexpression in hepatocytes in turn resulted in up-regulated or downregulated expression levels of SIRT1, respectively. The most fascinating finding in our study is that ATF6 was pulled down by SIRT1 antibody, indicating that SIRT1 is directly bound to and likely inhibits ATF6 dissociation into the cytoplasm, leading to the inhibition of ATF6mediated accumulation of LDs. In our study, a potential binding site for ATF6 was found in the SIRT1 promoter region, and ATF6 might directly deactivate SIRT1 transcriptional activity by directly binding to the corresponding promoter of SIRT1. Furthermore, the PLA also suggests that ATF6 can directly bind to SIRT1 in hepatocytes after RSV treatment. The results clearly demonstrate that RSV acts to enhance SIRT1 activity and expression through a positive feedback loop involving ATF6. The results of this study have also demonstrated that ATF6 is subjected to deacetylation mediated by SIRT1 after RSV treatment. The deacetylation of ATF 6 constitutes an important post-translational mechanism that controls the stability of the protein and activity of ATF6 (Fig. 7). However, the mechanism underlying the SIRT1ATF6 interaction needs further investigation.

\section{Conclusion}

This study revealed that RSV supplementation improves hepatic steatosis and reduces the accumulation of LDs in mouse liver and hepatocytes through the stimulation of SIRT1 and the dependent deacetylation and inactivation of ATF6, followed by a positive feedback loop for SIRT1 transcription associated with ATF6 binding to the SIRT1 promoter region. Our investigation provides an avenue in which to study NAFLD pathogenesis and develop 


\section{Cellular Physiology Cell Physiol Biochem 2018;51:2397-2420 and Biochemistry Published \begin{tabular}{l|l} 
DOI: 10.1159/000495898 & @ 2018 The Author(s). Published by S. Karger AG, Basel \\
www.karger.com/cpb
\end{tabular} \\ Zhou et al.: Resveratrol Ameliorates LDs Through SIRT1/ATF6}

new molecules for pharmaceutical interventions. This study also suggests that humans can achieve beneficial metabolic effects through lifestyle modifications and RSV supplementation, which would act by regulating the SIRT1/ATF6 pathway and its downstream processes.

\section{Abbreviations}

AMPK (AMP-activated protein kinase); ATF6 (activating transcription factor 6b); Zip (basic region-leucine zipper); ChIP (chromatin immunoprecipitation); CIDEC (cell death inducing DFFA like effector C); CR (calorie restriction); CREBH (cyclic adenosine monophosphate responsive element binding protein H); DMEM (Dulbecco's modified Eagle's medium); ER (endoplasmic reticulum); FA (fatty acid); FBS (fetal bovine serum); Fsp27 $\beta$ (fatspecific protein 27 $\beta$ ); GRP78 (glucose regulated protein 78); HDAC (histone deacetylase); HDL-C (high-density lipoprotein cholesterol); HFD (high-fat diet); IR (insulin resistance); KD (knockdown); LD (lipid droplet); LDL-C (low-density lipoprotein cholesterol); NAFLD (nonalcoholic fatty liver disease); NASH (non-alcoholic steatohepatitis); PA (palmitate acid); PLA (proximity ligation assay); PLIN1 (perilipin1); qRT-PCR (quantitative reverse transcription polymerase chain reaction); RSV (resveratrol); SDS (sodium dodecyl sulfate); SDS-PAGE (sodium dodecyl sulfate polyacrylamide gel electrophoresis); siRNA (small interfering RNA); SIRT (sirtuin); TG (triglyceride); UPR (unfolded protein response); WT (wild type).

\section{Acknowledgements}

This work was supported by grants from the National Natural Science Foundation of China (grant number: 81673154 and 81573131).

\section{Disclosure Statement}

The authors declare no conflicts of interest.

\section{References}

1 Neuschwander-Tetri BA: Non-alcoholic fatty liver disease. Bmc Med 2017;15:45.

2 Benedict M, Zhang X: Non-alcoholic fatty liver disease: An expanded review. World J Hepatol 2017;9:715732.

3 Kim S, Park S, Kim B, Kwon J: Toll-like receptor 7 affects the pathogenesis of non-alcoholic fatty liver disease. Sci Rep 2016;6:27849.

4 Townsend SA, Newsome PN: Review article: New treatments in non-alcoholic fatty liver disease. Aliment Pharmacol Ther 2017;46:494-507.

5 Dietrich P, Hellerbrand C: Non-alcoholic fatty liver disease, obesity and the metabolic syndrome. Best Pract Res Clin Gastroenterol 2014;28:637-653.

6 Gluchowski NL, Becuwe M, Walther TC, Farese RV: Lipid droplets and liver disease: From basic biology to clinical implications. Nat Rev Gastro Hepat 2017;14:343-355.

7 Yang H, Galea A, Sytnyk V, Crossley M: Controlling the size of lipid droplets: Lipid and protein factors. Curr Opin Cell Biol 2012;24:509-516.

8 Xu W, Wu L, Yu M, Chen FJ, Arshad M, Xia X, Ren H, Yu J, Xu L, Xu D, Li JZ, Li P, Zhou L: Differential roles of cell death-inducing DNA fragmentation factor-alpha-like effector (CIDE) proteins in promoting lipid droplet fusion and growth in subpopulations of hepatocytes. J Biol Chem 2016;291:4282-4293.

-9 Zhou L, Park SY, Xu L, Xia X, Ye J, Su L, Jeong KH, Hur JH, Oh H, Tamori Y, Zingaretti CM, Cinti S, Argente J, Yu M, Wu L, Ju S, Guan F, Yang H, Choi CS, Savage DB, Li P: Insulin resistance and white adipose tissue inflammation are uncoupled in energetically challenged Fsp27-deficient mice. Nat Commun 2015;6:5949. 


\section{Cellular Physiology Cell Physiol Biochem 2018;51:2397-2420

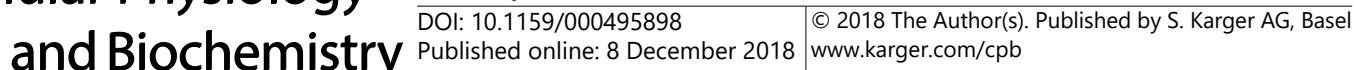

10 Li J, Liu G, Zhang F, Zhang Z, Xu Y, Li Q: Role of glycoprotein 78 and cidec in hepatic steatosis. Mol Med Rep 2017;16:1871-1877.

11 Sahini N, Borlak J: Genomics of human fatty liver disease reveal mechanistically linked lipid dropletassociated gene regulations in bland steatosis and nonalcoholic steatohepatitis. Transl Res 2016;177:4169.

12 Bedalov A, Chowdhury S, Simon JA: Biology, chemistry, and pharmacology of sirtuins. Methods Enzymol 2016;574:183-211.

13 Nassir F, Ibdah JA: Sirtuins and nonalcoholic fatty liver disease. World J Gastroenterol 2016;22:1008410092.

14 Deng XQ Chen LL, Li NX: The expression of SIRT1 in nonalcoholic fatty liver disease induced by high-fat diet in rats. Liver Int 2007;27:708-715.

15 Mariani S, Di Rocco G, Toietta G, Russo MA, Petrangeli E, Salvatori L: Sirtuins 1-7 expression in human adipose-derived stem cells from subcutaneous and visceral fat depots: Influence of obesity and hypoxia. Endocrine 2017;57:455-463.

16 Mariani S, Fiore D, Basciani S, Persichetti A, Contini S, Lubrano C, Salvatori L, Lenzi A, Gnessi L: Plasma levels of SIRT1 associate with non-alcoholic fatty liver disease in obese patients. Endocrine 2015;49:711716.

17 Purushotham A, Schug TT, Xu Q, Surapureddi S, Guo X, Li X: Hepatocyte-specific deletion of SIRT1 alters fatty acid metabolism and results in hepatic steatosis and inflammation. Cell Metab 2009;9:327-338.

$>18$ Shen X, Ellis RE, Sakaki K, Kaufman RJ: Genetic interactions due to constitutive and inducible gene regulation mediated by the unfolded protein response in C. Elegans. Plos Genet 2005;1:e37.

$>19$ Zhang C, Wang G, Zheng Z, Maddipati KR, Zhang X, Dyson G, Williams P, Duncan SA, Kaufman RJ, Zhang $\mathrm{K}$ : Endoplasmic reticulum-tethered transcription factor cAMP responsive element-binding protein, hepatocyte specific, regulates hepatic lipogenesis, fatty acid oxidation, and lipolysis upon metabolic stress in mice. Hepatology 2012;55:1070-1082.

-20 Xu MJ, Cai Y, Wang H, Altamirano J, Chang B, Bertola A, Odena G, Lu J, Tanaka N, Matsusue K, Matsubara T, Mukhopadhyay P, Kimura S, Pacher P, Gonzalez FJ, Bataller R, Gao B: Fat-Specific protein 27/CIDEC promotes development of alcoholic steatohepatitis in mice and humans. Gastroenterology 2015;149:10301041.

21 Chen Q Wang T, Li J, Wang S, Qiu F, Yu H, Zhang Y, Wang T: Effects of natural products on Fructose-Induced nonalcoholic fatty liver disease (NAFLD). Nutrients 2017;9:E96.

22 Chen S, Zhao X, Ran L, Wan J, Wang X, Qin Y, Shu F, Gao Y, Yuan L, Zhang Q, Mi M: Resveratrol improves insulin resistance, glucose and lipid metabolism in patients with non-alcoholic fatty liver disease: A randomized controlled trial. Digest Liver Dis 2015;47:226-232.

23 Zhang C, Yuan W, Fang J, Wang W, He P, Lei J, Wang C: Efficacy of resveratrol supplementation against Non-Alcoholic fatty liver disease: A Meta-Analysis of Placebo-Controlled clinical trials. Plos One 2016;11:e161792.

-24 Howitz KT, Bitterman KJ, Cohen HY, Lamming DW, Lavu S, Wood JG, Zipkin RE, Chung P, Kisielewski A, Zhang LL, Scherer B, Sinclair DA: Small molecule activators of sirtuins extend Saccharomyces cerevisiae lifespan. Nature 2003;425:191-196.

-25 Zhang Y, Chen M, Zhou Y, Yi L, Gao Y, Ran L, Chen S, Zhang T, Zhou X, Zou D, Wu B, Wu Y, Chang H, Zhu J, Zhang Q, Mi M: Resveratrol improves hepatic steatosis by inducing autophagy through the cAMP signaling pathway. Mol Nutr Food Res 2015;59:1443-1457.

-26 Um JH, Park SJ, Kang H, Yang S, Foretz M, McBurney MW, Kim MK, Viollet B, Chung JH: AMP-activated protein kinase-deficient mice are resistant to the metabolic effects of resveratrol. Diabetes 2010;59:554563.

27 Zhou JN, Zeng Q Wang HY, Zhang B, Li ST, Nan X, Cao N, Fu CJ, Yan XL, Jia YL, Wang JX, Zhao AH, Li ZW, Li YH, Xie XY, Zhang XM, Dong Y, Xu YC, He LJ, Yue W, Pei XT: MicroRNA-125b attenuates epithelial-mesenchymal transitions and targets stem-like liver cancer cells through small mothers against decapentaplegic 2 and 4 . Hepatology 2015;62:801-815.

28 Chen ML, Yi L, Jin X, Xie Q, Zhang T, Zhou X, Chang H, Fu YJ, Zhu JD, Zhang QY, Mi MT: Absorption of resveratrol by vascular endothelial cells through passive diffusion and an SGLT1-mediated pathway. J Nutr Biochem 2013;24:1823-1829. 


\section{Cellular Physiology Cell Physiol Biochem 2018;51:2397-2420 and Biochemistry \begin{tabular}{l|l} 
DOI: 10.1159/000495898 2018 The Author(s). Published by S. Karger AG, Basel \\
w 2018 ww.karger.com/cpb
\end{tabular}

29 Nicolai A, Li M, Kim DH, Peterson SJ, Vanella L, Positano V, Gastaldelli A, Rezzani R, Rodella LF, Drummond G, Kusmic C, L'Abbate A, Kappas A, Abraham NG: Heme oxygenase-1 induction remodels adipose tissue and improves insulin sensitivity in obesity-induced diabetic rats. Hypertension 2009;53:508-515.

30 Chen ML, Yi L, Jin X, Liang XY, Zhou Y, Zhang T, Xie Q, Zhou X, Chang H, Fu YJ, Zhu JD, Zhang QY, Mi MT: Resveratrol attenuates vascular endothelial inflammation by inducing autophagy through the cAMP signaling pathway. Autophagy 2013;9:2033-2045.

-31 Sinha RA, Farah BL, Singh BK, Siddique MM, Li Y, Wu Y, Ilkayeva OR, Gooding J, Ching J, Zhou J, Martinez L, Xie S, Bay BH, Summers SA, Newgard CB, Yen PM: Caffeine stimulates hepatic lipid metabolism by the autophagy-lysosomal pathway in mice. Hepatology 2014;59:1366-1380.

-32 Veiga F, Graus-Nunes F, Rachid TL, Barreto AB, Mandarim-de-Lacerda CA, Souza-Mello V: Anti-obesogenic effects of WY14643 (PPAR-alpha agonist): Hepatic mitochondrial enhancement and suppressed lipogenic pathway in diet-induced obese mice. Biochimie 2017;140:106-116.

-33 Zhou Q, Gu Y, Lang H, Wang X, Chen K, Gong X, Zhou M, Ran L, Zhu J, Mi M: Dihydromyricetin prevents obesity-induced slow-twitch-fiber reduction partially via FLCN/FNIP1/AMPK pathway. Biochim Biophys Acta 2017;1863:1282-1291.

34 Huang Y, Zhou J, Huang Y, He J, Wang Y, Yang C, Liu D, Zhang L, He F: SARI, a novel target gene of glucocorticoid receptor, plays an important role in dexamethasone-mediated killing of B lymphoma cells. Cancer Lett 2016;373:57-66.

-35 Shanthi P. Kanthala YLSS: A peptidomimetic with a chiral switch is an inhibitor of epidermal growth factor receptor heterodimerization. Oncotarget 2017;8:74244-74262.

-36 Quan HY, Kim DY, Kim SJ, Jo HK, Kim GW, Chung SH: Betulinic acid alleviates non-alcoholic fatty liver by inhibiting SREBP1 activity via the AMPK-mTOR-SREBP signaling pathway. Biochem Pharmacol 2013;85:1330-1340.

-37 Wang GL, Fu YC, Xu WC, Feng YQ Fang SR, Zhou XH: Resveratrol inhibits the expression of SREBP1 in cell model of steatosis via Sirt1-FOXO1 signaling pathway. Biochem Biophys Res Commun 2009;380:644-649.

38 Xu X, Park JG, So JS, Lee AH: Transcriptional activation of Fsp27 by the liver-enriched transcription factor CREBH promotes lipid droplet growth and hepatic steatosis. Hepatology 2015;61:857-869.

-39 Razavi ZM, Telkabadi MH, Bahmani F, Salehi B, Farshbaf S, Asemi Z: The effects of DASH diet on weight loss and metabolic status in adults with non-alcoholic fatty liver disease: A randomized clinical trial. Liver Int 2016;36:563-571.

40 Tanaka N, Takahashi S, Matsubara T, Jiang C, Sakamoto W, Chanturiya T, Teng R, Gavrilova O, Gonzalez FJ: Adipocyte-specific disruption of fat-specific protein 27 causes hepatosteatosis and insulin resistance in high-fat diet-fed mice. J Biol Chem 2015;290:3092-3105.

41 Donnelly KL, Smith CI, Schwarzenberg SJ, Jessurun J, Boldt MD, Parks EJ: Sources of fatty acids stored in liver and secreted via lipoproteins in patients with nonalcoholic fatty liver disease. J Clin Invest 2005;115:1343-1351.

42 Tang LY, Chen Y, Rui BB, Hu CM: Resveratrol ameliorates lipid accumulation in HepG2 cells, associated with down-regulation of lipin1 expression. Can J Physiol Pharmacol 2015:1-5.

43 Xu L, Zhou L, Li P: CIDE proteins and lipid metabolism. Arterioscler Thromb Vasc Biol 2012;32:1094-1098.

-44 Matsusue K, Kusakabe T, Noguchi T, Takiguchi S, Suzuki T, Yamano S, Gonzalez FJ: Hepatic steatosis in leptin-deficient mice is promoted by the PPARgamma target gene Fsp27. Cell Metab 2008;7:302-311.

45 Nishino N, Tamori Y, Tateya S, Kawaguchi T, Shibakusa T, Mizunoya W, Inoue K, Kitazawa R, Kitazawa S, Matsuki Y, Hiramatsu R, Masubuchi S, Omachi A, Kimura K, Saito M, Amo T, Ohta S, Yamaguchi T, Osumi T, Cheng J et al.: FSP27 contributes to efficient energy storage in murine white adipocytes by promoting the formation of unilocular lipid droplets. J Clin Invest 2008;118:2808-2821.

46 Toh SY, Gong J, Du G, Li JZ, Yang S, Ye J, Yao H, Zhang Y, Xue B, Li Q Yang H, Wen Z, Li P: Up-regulation of mitochondrial activity and acquirement of brown adipose tissue-like property in the white adipose tissue of fsp27 deficient mice. Plos One 2008;3:e2890.

47 Asada R, Kanemoto S, Kondo S, Saito A, Imaizumi K: The signalling from endoplasmic reticulum-resident bZIP transcription factors involved in diverse cellular physiology. J Biochem 2011;149:507-518.

-48 Carr RM, Ahima RS: Pathophysiology of lipid droplet proteins in liver diseases. Exp Cell Res 2016;340:187192.

-49 Sun Z, Gong J, Wu H, Xu W, Wu L, Xu D, Gao J, Wu JW, Yang H, Yang M, Li P: Perilipin1 promotes unilocular lipid droplet formation through the activation of Fsp27 in adipocytes. Nat Commun 2013;4:1594. 


\section{Cellular Physiology Cell Physiol Biochem 2018;51:2397-2420

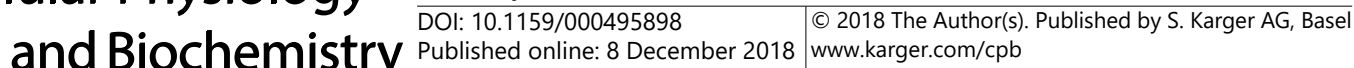

50 Straub BK, Stoeffel P, Heid H, Zimbelmann R, Schirmacher P: Differential pattern of lipid droplet-associated proteins and de novo perilipin expression in hepatocyte steatogenesis. Hepatology 2008;47:1936-1946.

-51 Ahmed B, Liu S, Si H: Antiadipogenic effects and mechanisms of combinations of genistein, Epigallocatechin-3-Gallate, and/or resveratrol in preadipocytes. J Med Food 2017;20:162-170.

52 Fremont L: Biological effects of resveratrol. Life Sci 2000;66:663-673.

53 Pan MH, Lai CS, Tsai ML, Ho CT: Chemoprevention of nonalcoholic fatty liver disease by dietary natural compounds. Mol Nutr Food Res 2014;58:147-171.

-54 Heeboll S, Thomsen KL, Pedersen SB, Vilstrup H, George J, Gronbaek H: Effects of resveratrol in experimental and clinical non-alcoholic fatty liver disease. World J Hepatol 2014;6:188-198.

-55 Aguirre L, Portillo MP, Hijona E, Bujanda L: Effects of resveratrol and other polyphenols in hepatic steatosis. World J Gastroenterol 2014;20:7366-7380.

56 Faghihzadeh F, Hekmatdoost A, Adibi P: Resveratrol and liver: A systematic review. J Res Med Sci 2015;20:797-810.

57 Zang M, Xu S, Maitland-Toolan KA, Zuccollo A, Hou X, Jiang B, Wierzbicki M, Verbeuren TJ, Cohen RA: Polyphenols stimulate AMP-activated protein kinase, lower lipids, and inhibit accelerated atherosclerosis in diabetic LDL receptor-deficient mice. Diabetes 2006;55:2180-2191.

\$58 Ji G, Wang Y, Deng Y, Li X, Jiang Z: Resveratrol ameliorates hepatic steatosis and inflammation in methionine/choline-deficient diet-induced steatohepatitis through regulating autophagy. Lipids Health Dis 2015;14:134.

59 Poulsen MM, Larsen JO, Hamilton-Dutoit S, Clasen BF, Jessen N, Paulsen SK, Kjaer TN, Richelsen B, Pedersen SB: Resveratrol up-regulates hepatic uncoupling protein 2 and prevents development of nonalcoholic fatty liver disease in rats fed a high-fat diet. Nutr Res 2012;32:701-708.

60 El-Mowafy AM, El-Mesery ME, Salem HA, Al-Gayyar MM, Darweish MM: Prominent chemopreventive and chemoenhancing effects for resveratrol: Unraveling molecular targets and the role of C-reactive protein. Chemotherapy 2010;56:60-65.

-61 Andrade JM, Paraiso AF, de Oliveira MV, Martins AM, Neto JF, Guimaraes AL, de Paula AM, Qureshi M, Santos SH: Resveratrol attenuates hepatic steatosis in high-fat fed mice by decreasing lipogenesis and inflammation. Nutrition 2014;30:915-919.

62 Stunkel W, Campbell RM: Sirtuin 1 (SIRT1): The misunderstood HDAC. J Biomol Screen 2011;16:11531169.

63 Wu T, Liu YH, Fu YC, Liu XM, Zhou XH: Direct evidence of sirtuin downregulation in the liver of nonalcoholic fatty liver disease patients. Ann Clin Lab Sci 2014;44:410-418.

64 Fei W, Wang H, Fu X, Bielby C, Yang H: Conditions of endoplasmic reticulum stress stimulate lipid droplet formation in Saccharomyces cerevisiae. Biochem J 2009;424:61-67.

65 Yamamoto K, Takahara K, Oyadomari S, Okada T, Sato T, Harada A, Mori K: Induction of liver steatosis and lipid droplet formation in ATF6alpha-knockout mice burdened with pharmacological endoplasmic reticulum stress. Mol Biol Cell 2010;21:2975-2986.

-66 Lee JS, Mendez R, Heng HH, Yang ZQ, Zhang K: Pharmacological ER stress promotes hepatic lipogenesis and lipid droplet formation. Am J Transl Res 2012;4:102-113.

-67 Ozcan U, Cao Q, Yilmaz E, Lee AH, Iwakoshi NN, Ozdelen E, Tuncman G, Gorgun C, Glimcher LH, Hotamisligil GS: Endoplasmic reticulum stress links obesity, insulin action, and type 2 diabetes. Science 2004;306:457461.

68 Lee AH, Scapa EF, Cohen DE, Glimcher LH: Regulation of hepatic lipogenesis by the transcription factor XBP1. Science 2008;320:1492-1496.

69 Lee HK, Xiang C, Cazacu S, Finniss S, Kazimirsky G, Lemke N, Lehman NL, Rempel SA, Mikkelsen T, Brodie C: GRP78 is overexpressed in glioblastomas and regulates glioma cell growth and apoptosis. Neuro Oncol 2008;10:236-243.

70 Schroder M, Kaufman RJ: The mammalian unfolded protein response. Annu Rev Biochem 2005;74:739789.

71 Guan M, Fousek K, Jiang C, Guo S, Synold T, Xi B, Shih CC, Chow WA: Nelfinavir induces liposarcoma apoptosis through inhibition of regulated intramembrane proteolysis of SREBP-1 and ATF6. Clin Cancer Res 2011;17:1796-1806. 


\section{Cellular Physiology Cell Physiol Biochem 2018;51:2397-2420 \begin{tabular}{ll|l|l} 
DOI: 10.1159/000495898 & $\begin{array}{l}\text { O } 2018 \text { The Author(s). Published by S. Karger AG, Basel } \\
\text { www.karger.com/cpb }\end{array}$ \\
\hline and Biochemistry
\end{tabular}}

72 Baumeister P, Luo S, Skarnes WC, Sui G, Seto E, Shi Y, Lee AS: Endoplasmic reticulum stress induction of the Grp78/BiP promoter: Activating mechanisms mediated by YY1 and its interactive chromatin modifiers. Mol Cell Biol 2005;25:4529-4540.

73 Li F, Yang Y, Yang L, Wang K, Zhang X, Zong Y, Ding Y, Wang C, Zhang L, Ji G: Resveratrol alleviates FFA and $\mathrm{CCl} 4$ induced apoptosis in HepG2 cells via restoring endoplasmic reticulum stress. Oncotarget 2017;8:43799-43809.

74 Zhang X, Yu S, Galson DL, Luo M, Fan J, Zhang J, Guan Y, Xiao G: Activating transcription factor 4 is critical for proliferation and survival in primary bone marrow stromal cells and calvarial osteoblasts. J Cell Biochem 2008;105:885-895.

75 Zhu H, Xia L, Zhang Y, Wang H, Xu W, Hu H, Wang J, Xin J, Gang Y, Sha S, Xu B, Fan D, Nie Y, Wu K: Activating transcription factor 4 confers a multidrug resistance phenotype to gastric cancer cells through transactivation of SIRT1 expression. Plos One 2012;7:e31431. 